\title{
An overview on robust design hybrid metamodeling: Advanced methodology in process optimization under uncertainty
}

\author{
Amir Parnianifard ${ }^{\mathrm{a}}$, A.S. Azfanizam ${ }^{a}$, M.K.A. Ariffin ${ }^{\mathrm{a}}$ and M.I.S. Ismail ${ }^{\mathrm{a}}$
}

${ }^{a}$ Department of Mechanical and Manufacturing Engineering, Faculty of Engineering, Universiti Putra Malaysia, 43400 UPM Serdang, Selangor, Malaysia

\section{CHRON I C LE}

\section{Article history:}

Received January 152017

Received in Revised Format

April 12017

Accepted May 202017

Available online

May 262017

Keywords:

Robust design

Metamodeling

Uncertainty

Process optimization

\begin{abstract}
A B S T R A C T
Nowadays, process optimization has been an interest in engineering design for improving the performance and reducing cost. In practice, in addition to uncertainty or noise parameters, a comprehensive optimization model must be able to attend other circumstances which might be imposed in problems under real operational conditions such as dynamic objectives, multiresponses, various probabilistic distribution, discrete and continuous data, physical constraints to design parameters, performance cost, computational complexity and multi-process environment. The main goal of this paper is to give a general overview on topics with brief systematic review and concise discussions about the recent development on comprehensive robust design optimization methods under hybrid aforesaid circumstances. Both optimization methods of mathematical programming based on Taguchi approach and robust optimization based on scenario sets are briefly described. Metamodels hybrid robust design is discussed as an appropriate methodology to decrease computational complexity in problems under uncertainty. In this context, the authors' policy is to choose important topics for giving a systematic picture to those who wish to be more familiar with recent studies about robust design optimization hybrid metamodels, also by attending real circumstances in practice. In particular, production and project management are considered as two important methodologies that could be improved by applications of advanced robust design combining with metamodel methods.
\end{abstract}

\section{Introduction}

In the new comprehensive world with rapid progress in technology, all company and organization have to improve the quality of their processes to achieve suitable flexibility and keeping their survival among other rivals in the extremely competitive environment. Most techniques and methods have been presented to help engineers for optimizing the company's processes to achieve the highest quality with minimum costs. In this context the term of optimization means finding the best levels of design variables set $(X)$ according to one or multi objectives $(f(X))$ while keeping design variables within their constraints $(g(X))$. Such constraints can be designed by equalities or inequalities which limit the design space to look for the best solution. However, a general framework in mathematical programing model can be depicted as:

* Corresponding author Tel.: +601123058983

E-mail: gs46398@student.upm.edu.my (A.Parnianifard)

(C) 2018 Growing Science Ltd. All rights reserved. doi: $10.5267 /$ j. ijiec.2017.5.003 
min or $\max : \quad f_{i}(X), \quad i=1,2, \ldots, I$

subject to:

$$
\begin{aligned}
g_{j}(X) \leq 0, & j=1,2, \ldots, J \\
h_{l}(X)=0, & l=1,2, \ldots, L
\end{aligned}
$$

where $f_{i}(X)$ shows the objectives set (single or multi) and $g_{j}(X), h_{l}(X)$ illustrate the set of inequality and quality constraints (Beyer \& Sendhoff, 2007). In particular, there are a number of mathematical formulations in literature which try to find optimum and feasible solution using constraints. Some of them are Linear Programming (LP), Mixed Integer Programming (MIP), Second Order Cone Programming (SOCP), and Semidefinite Programming (SDP) problems.

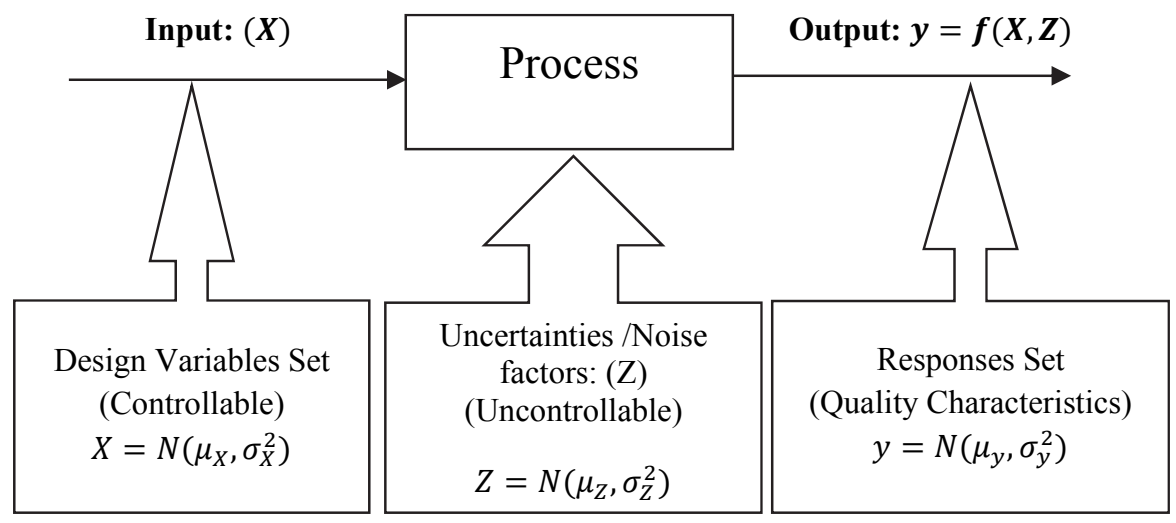

Fig. 1. An overview of process that shows Input, Output, and Uncertainties sets

In practice, most processes have been faced by uncontrollable parameters as uncertainties and noise factors which affect on process performance. A general overview of the process is illustrated in Fig. 1. In process quality approach a process consists of three main parts which are design variables (controllable), uncertainties or noise factors (uncontrollable), and quality characteristics (responses). This is the duty of design engineer to identify what is input, what is output and what is an ideal function for designing the process (Phadke, 1989). Such a considering uncertainty or noise parameter in the process leads to introduce Robust Design Optimization (RDO) methods. The term of robust design has been attached by Genichi Taguchi as a pioneer in the word of robust design philosophy (Park, 1996; Park \& Antony, 2008; Phadke, 1989). According to Park (1996) robust design is an engineering methodology for optimizing the product and process conditions which are minimally sensitive to the various causes of variation, and that produce high-quality products with low development and designing costs. Ben-Tal et al. (2009) mentioned that the data of real world optimization problems more often are uncertain and not identified exactly when the problem is being solved. The reasons for uncertainty in data are classified in some parts. The first part is to measurement or estimation errors which arise from the impossibility to estimate the exact data on characteristics of physical processes. Second, implementation errors arising from the impossibility to implement an exact solution as it is estimated before. In real word optimization problems, it is desirable to consider the possibility of shifting the problem into meaningless due to the existence of even a small uncertainty. Furthermore, due to adding uncertainties and noise factors into the model, the computational complexity in design problems have incresed in engineering design. The expensive analysis and simulation processes are due to computation burden which caused by the physical or computer testing of data. Approximation or metamodeling techniques have been often used to address such a challenge. Various engineering disciplines including statistics, mathematics, computer science have been employed to develop metamodeling techniques (Wang \& Shan, 2007). Metamodeling techniques have been used to avoid intensive computational and numerical analysis, which might squander times and resource for estimating model's parameters especially under uncertain or noisy 
conditions. This study contributes to present an analytical review of references to offer a comprehensive viewpoint related to a particular field of interest. In addition, it is to identify lack of attention to particular areas of research.

\section{The proposed method}

The main purpose of literature review is to identify, evaluate and interprete most relevant available studies related to the particular field of research. Our strategy for collecting, reviewing and analyzing resources in literature is mentioned as three phases:

i. As primary sources, five electronic databases were attended to collect relevant studies. The electronic databases which applied in search process are listed in Table 1.

\section{Table 1}

Electronic source (database)

\begin{tabular}{lc}
\hline Electronic Source & URL \\
\hline Science Direct & http://sciencedirect.com/ \\
Springer Link & http://link.springer.com/ \\
Wiley & http://onlinelibrary.wiley.com/ \\
IEEE Xplore & http://ieeexplore.ieee.org/ \\
Google Scholar & $\mathrm{https://scholar.google.com/}$ \\
\hline
\end{tabular}

ii. Different keywords and their combinations were used to search relevant resources in literature from mentioned electronic databases. Note that, this context is focused for illustrating the recent development of robust design optimization particulary with employing metamodels and its application in two different types of relevant processes in management science consist of production management and project management. Moreover, a certain combination of keywords was used to filter results, which are "Robust design Optimization", "Robust Metamodel(ing)", and Process Optimization" with using the conjunction 'AND' by each term of 'under Uncertainty", or "Noise Factors". Notably, references which mentioned in some relevant literature review could be employed to recognize some appropriate articles.

iii. Totally, our findings consist of above 500 different resources in the literature. Based on abstract and conclusion which are associated with interesting topics, 150 articles were filtered. The magnitude (percent) of total articles based on published year is shown in Fig. 2, and as can be seen from the figure, the time period for the most proportion of reviewed resources was belonged to recent years to ensure up-to-date resources included.

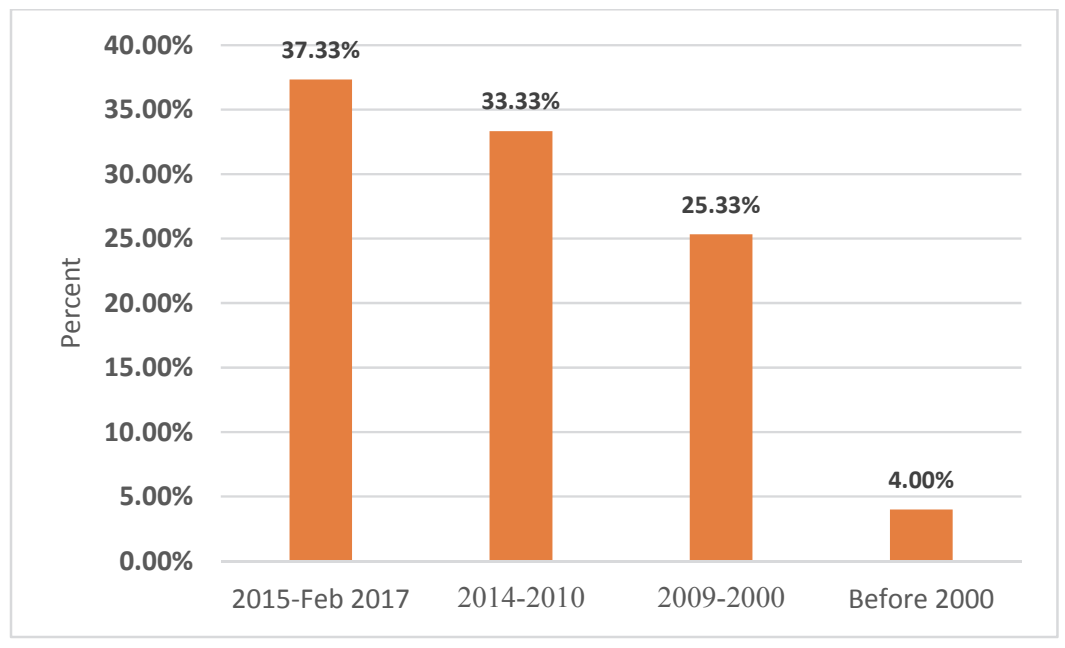

Fig. 2. Filtered articles based on published year - total: 150 articles 
Totally, our findings were consist of above 500 different resources in the literature. Based on abstract and conclusion which are associated with interesting topics, 150 articles were filtered. The magnitude (percent) of total articles based on published year is shown in Fig. 2, and as can be seen from the figure, the time period for the most proportion of reviewed resources belongs to recent years to ensure up-todate resources included. For each article, an in-depth review was done and analytical results were gathered in the same database. Extracted information was defined based on two different terms included objective and methodology. Relevant extracted information are analytically discussed in section 4.

This paper is organized as follows. In section 2, the review strategy and procedure are described. Section 3 provides some general information about the relevant topics. The systematic findings and results which have been achieved by review resources are explained in section 4 . Finally, the paper is concluded in section 5 .

\section{Basic information}

Process optimization is the discipline of adjusting a process to optimize some specified set of parameters without violating some constraints. The most common goals are minimizing cost and maximizing throughput and/or efficiency. When optimizing a process, the goal is to maximize one or more of the process specifications, while keeping all others within their constraints. In real world, to achieve an accurate solution in model, we need to consider some circumstances in designing and modeling a process. In practice a process definitely has been affected by most external and environmental uncertainty or noise factors (Ben-Tal et al., 2009) that cause to response quality specifications be far from ideal points and have variances. In addition, each process has to coincide itself to be softly compatible with changing in its condition to keep flexibility and reduce extra cost which might impose to process for adjusting with new conditions (Ehrgott et al., 2014; Haobo et al., 2015). For instance, in the relevant process in management science, customer needs (Gasior \& Józefczyk, 2009), external diplomatic rules, economical pressure, local and global environmental policies (Geletu \& Li, 2014) and managing rules can be changed over time and it changes the process goals and ideal points of responses. So, it is the duty of engineers to design flexible processes which can be adjusted immediately coincide to new circumstances as soon as possible. Robust design optimization methodology plays an important role to develop high reliability in the process (Bergman et al., 2009), in order to robust design bring an insensibility for the process.

On the other side, considering most important circumstances in the processes such as uncertainty or noise parameters, dynamic goals over time, multi-responses, and variety types of data can increase the computational complexity. Furthermore, in order to estimate parameters of the process and their relevant relationship, most numbers of physical or computer experiments might be executed to make the adequate approximation. Also, those experiments could be imposed huge costs to examiners and other responses. Therefore, meta-models could be used to simulate and approximate the relationship between output and inputs parameters in the process. The metamodel and its counterpart as robust design approach have been studied, to guarantee that the problem keeps its tractability under uncertainties with at least computational costs (Dellino et al., 2015). Naturally, it is up to the process engineer to decide which method is the best for a particular problem. However, it seems appropriate to employ methods which include meta-models for Robust Design Optimization (RDO) of computationally expensive models, to avoid the huge burden of calculations (Bossaghzadeh et al., 2015; Persson \& Ölvander, 2013).

In this part, relevant methodologies which throughout the review of articles have been extracted are briefly mentioned. First, basic mathematical and statistical tools around robust design optimization based on Taguchi approach are discussed. Then briefly robust optimization based on scenario approach is mentioned, which mainly proposed by Ben-Tal et al. (2009). Furthermore, common metamodeling methodologies are introduced and explained that recently those methods have been interested in combining with robust design to investigate the robustness solution in a model with minimum computational costs. 


\subsection{Robust Design Optimizationnt}

Robust Design Optimization (RDO) is an engineering methodology for improving productivity and flexibility during research and in practice. The idea behind RDO is to improve the quality of a process by minimizing the effects of variation without eliminating the causes (since they are too difficult or too expensive to control). The most processes are affected by external uncontrollable factors in real condition, which cause quality characteristics being far from ideal points and have variation. In process robustness studies, it is desirable to minimize the influence of noise factors and uncertainty on the process and simultaneously determine the levels of design (control) factors in order to optimize the overall response, or in another sense, optimizing product and process which are minimally sensitive to the various causes of variance (Park \& Antony, 2008).

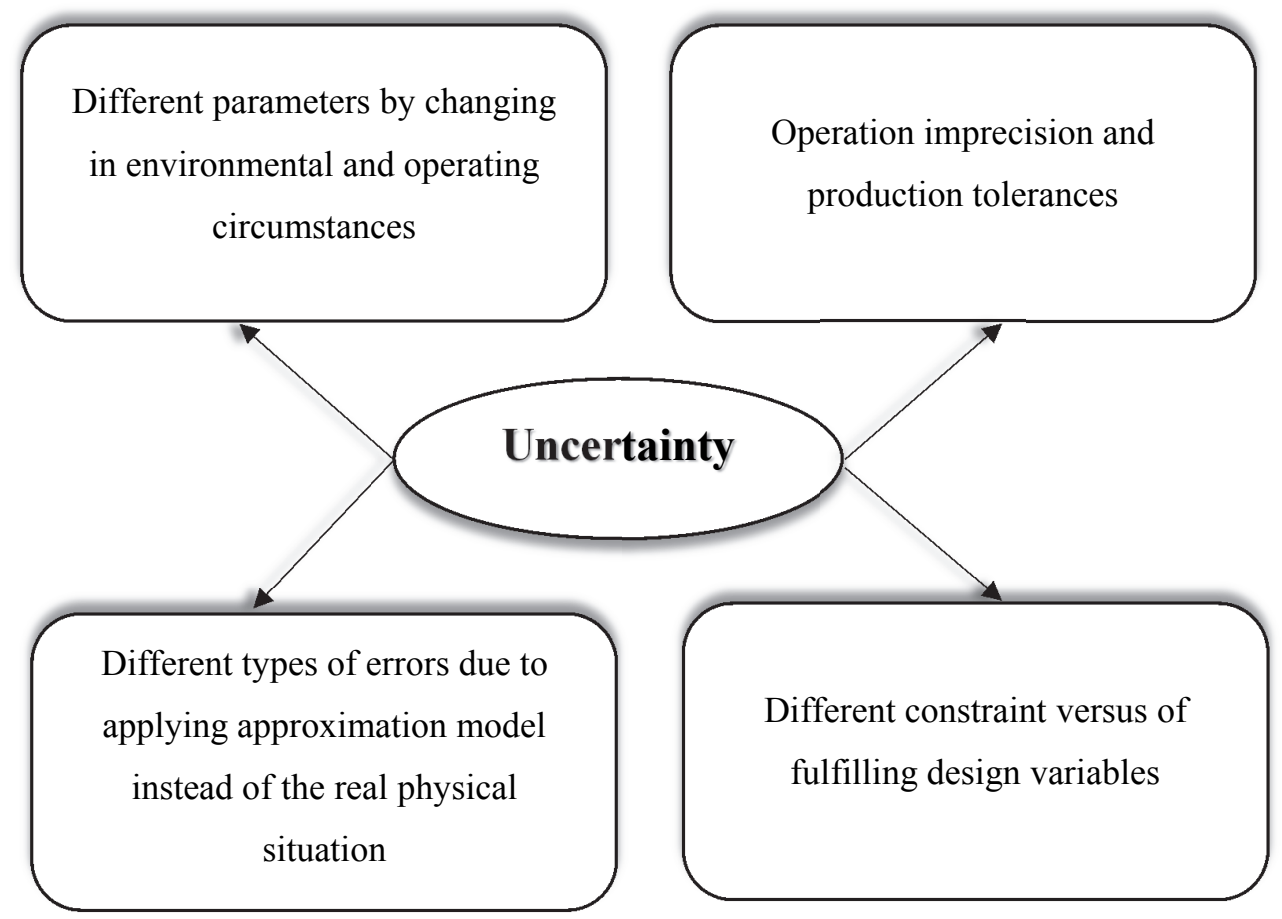

Fig. 3. Different types of uncertainties

\subsubsection{Different sources of uncertainty}

Beyer and Sendhoff (2007) described four different types of uncertainties which a process might be collided by them as shown in Fig. 3. Another similar classification has been presented by Yjin and Branke (2005) which divided uncertainties into four categories, included noise in fitness functions, search for robust solutions, approximation error in the fitness function, and fitness functions changing over time. Also, another classification was proposed by Ho (1989) for production processes that divided uncertainty into two groups. First, an environmental uncertainty which includes uncertainties related to the process of production such as demand or supply uncertainty. Second, system uncertainty beyond uncertainties within the production process such as operation yield uncertainty, production lead time uncertainty, quality uncertainty, failure of the production system and changes to product structure (Mula et al., 2006).

\subsubsection{Classification of robust optimization models}

Robust design with uncertainties has been distinguished a robustness design for constraints as well as objectives. There are various number of methods associated with robust design methodology in literature with different types of classification. One of the common classification is depicted in Fig. 4. As can be 
seen from this figure, robust optimization methods can be divided into two types of probabilistic and non-probabilistic approaches (Cao et al., 2015). In probabilistic or stochastic robust optimization methods, the designer performs the problem by employing the probability distribution of variables, particularly the mean and variation of uncertain or noise variables. It is clear that accuracy of obtained optimization results strongly depends on the accuracy of assumed probability distribution, in (Ardakani et al., 2009; Khan et al., 2015; Nha et al., 2013; Park \& Leeds, 2015; Simpson et al., 2001) some applications of these types of robust optimization methods have been illustrated. Sometimes, the probability distribution of variables might be unknown or often difficult to obtain. Moreover, nonprobabilistic or deterministic (distribution-free) methods could be used without depending on the size of variable variation region. This types of methods attempt to find robustness and optimum solution by recording different uncertainty sets in objective and constraint space. The main gap for these methods are that when uncertainties change in their variation region and previous results miss their validation, so it needs to designer evaluate problem again (Cao et al., 2015). To be more familiar with these types of methods see (Ben-Tal et al., 2009; Bertsimas et al., 2011; Ehrgott et al., 2014; Ide \& Schobel, 2016; Salomon et al., 2014).

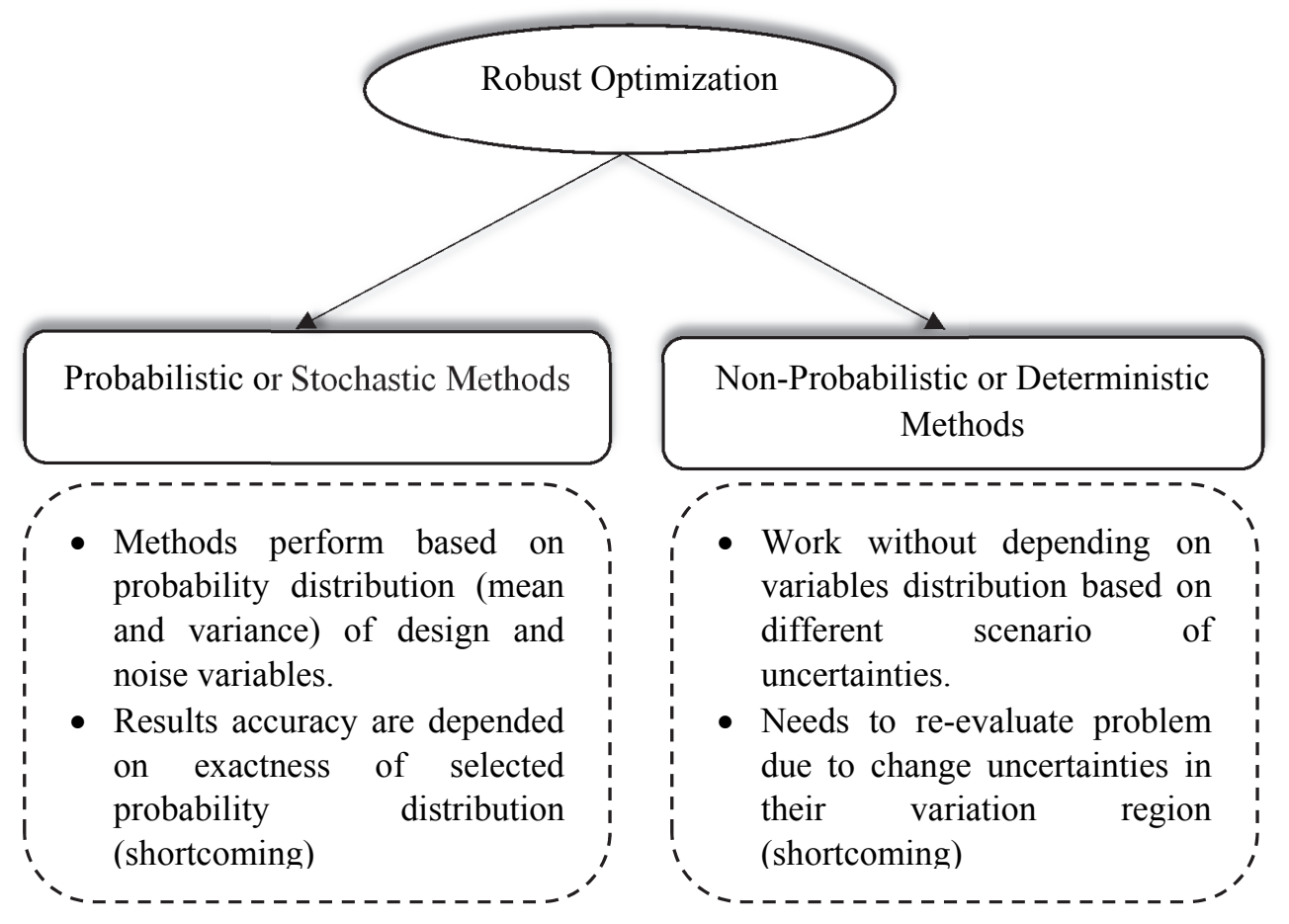

Fig. 4. Classification of robust optimization methods

Among the study in literature, other classification of robust optimization problem could be defined when they are divided into two categories (Park \& Lee, 2006). The first robust design optimization is based on Taguchi's approach (Park \& Lee, 2006; Park \& Antony, 2008; Phadke, 1989) and the second robust optimization is based on uncertainty scenario sets (different combination of uncertainties) (Ben-Tal et al., 2009; Bertsimas et al., 2011; Gabrel et al., 2014). In this context, we concentrate more in Taguchi philosophy for the uncertain and noisy condition of the problem in the real world. Recent comprehensive overview of historical and technical aspects of robust optimization methods can be found in (Bertsimas et al., 2011; Beyer \& Sendhoff, 2007; Dellino et al., 2015; Gabrel et al., 2014; Geletu \& Li, 2014; Wang \& Shan, 2011).

\subsubsection{Robust Design Optimization Based on Taguchi's Approach}

The robust design methodology was introduced by Dr. Genichi Taguchi after the end of the Second World War and this method has developed over the last five decades. Quality control and experimental 
design had strongly affected by Taguchi as a Japanese engineer in the 1980s and 1990s. Taguchi proposed that the term of quality should not be supposed just as a product being inside of specifications, but in addition to attending the variation from the target point (Shahin, 2006).

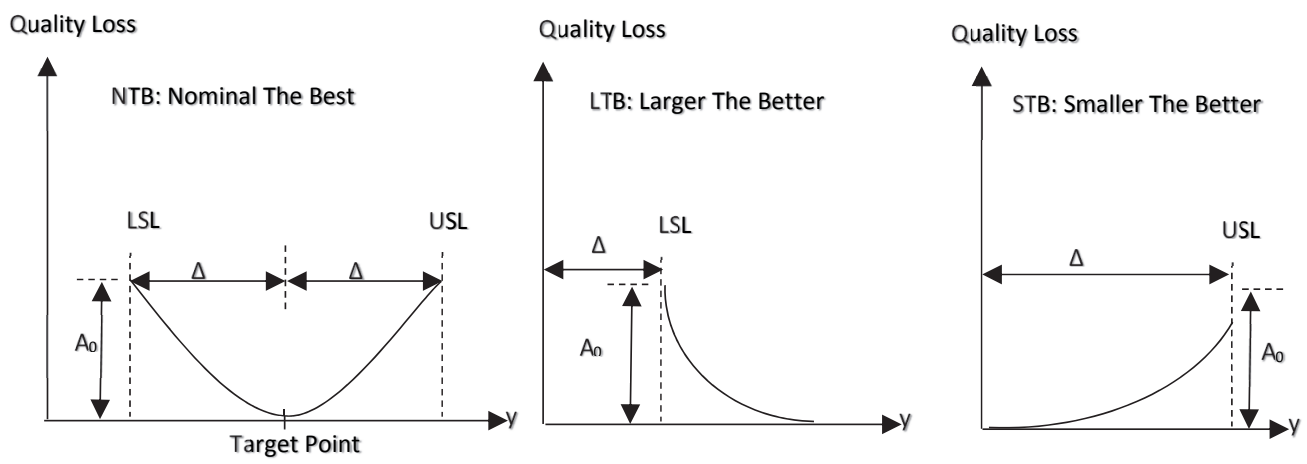

Fig. 5. Quality loss for three different types of quality characteristic, NTB, LTB, STB

Phadke (1989) defined robust design as an "engineering methodology for improving productivity during research and development so that high-quality products can be produced quickly and at low cost". The idea behind the robust design is to increase the quality of a process by decreasing the effects of variation without eliminating the causes since they are too difficult or too expensive to control. Park (1996) classified the major sources of variation into six categories included man, machine, method, material, measurement, and environment. The method of robust design is being into types of an off-line quality control method that design process before proceeding stage to improve productability and flexibility by creating process insensitive against environmental changeability and component variations. Totally, designing process that has a minimum sensitivity to variations in uncontrollable factors is the end result of robust design. The foundation of robust design has been structured by Taguchi on parameter design in a narrow sense. The concept of robust design has many aspects, where three aspects among them are more outstanding (Park \& Antony, 2008):

1- Investigating a set of conditions for design variables which are insensitive (robust) against noise factor variation.

2- Finding at least variation in a performance around target point.

3- Achieving the minimum number of experiments by employing orthogonal arrays.

Robust design based on Taguchi approach has employed some statistically and analytically tools such as orthogonal arrays and Signal to Noise (SN) ratios. Furthermore, many designed experiments for determining the adequate combination of factor levels which are used in each run of experiments and for analyzing data with their interaction have been applied a fractional factorial matrix that called orthogonal arrays. The ratio between the power of the signal and the power of noise is called the signal to noise ratio (SN = power of signal/power of noise). The larger numerical value of SN ratio is more desirable for process. There are three types of SN ratios which are available in robust design method depending on the type of quality characteristic, the Larger The Better (LTB), the Smaller the Better (STB), Nominal The Best (NTB). Both concepts of signal to noise ratio and orthogonal arrays have been described by most studies after first introducing by Taguchi in 1980s, so for more information see (Park, 1996; Park \& Antony, 2008; Phadke, 1989). 
Table 2

Taguchi's approach on quality loss function

\begin{tabular}{ccc}
\hline Quality Characteristic Type & Expected Quality Loss Function & Quality loss coefficient \\
\hline Nominal the Best & $Q=C_{0}\left[(\mu-T)^{2}+\sigma^{2}\right]$ & $C_{0}=\frac{A_{0}}{\Delta^{2}}$ \\
Smaller The Better & $Q=C_{0}\left[\mu^{2}+\sigma^{2}\right]$ & $C_{0}=\frac{A_{0}}{\Delta^{2}}$ \\
Larger The Better & $Q=C_{0}\left[\left(\frac{1}{\mu^{2}}\right)\left(1+3 \sigma^{2} / \mu^{2}\right)\right]$ & $C_{0}=A_{0} \Delta^{2}$ \\
\hline
\end{tabular}

Taguchi represented the concept of quality loss as an average amount of total loss that compels to society because of deviance from the ideal point and be variance in responses. Moreover, this function for each type of quality characteristics tries to create a trade-off between mean and variance. Fig. 5 depicts the expected loss function based on the well-known classification of quality characteristics into three different types of NTB, STB, and LTB. In addition, the expected quality loss function based on Taguchi's approach for all three types of quality characteristics are represented in Table 2. Where in illustrated equations in Table 2, $Q$ shows the expected quality loss and $\mu, \sigma^{2}, \mathrm{~T}$, and $C_{0}$ respectively are quality characteristic mean, variance, target and loss coefficient. The quality loss coefficient $C_{0}$ for each type of quality characteristic can be computed based on information about the losses in monetary terms when process specification is outside of the customer tolerance limits which is extracted from customer's point of view as shown in Fig. 5. In addition, $A_{0}$ is introduced as a cost of repair or replacement when the quality characteristics performance has the distance of $\Delta$ from target point (Phadke, 1989). Recently, the concept of quality loss function has been extended by some studies such as Sharma and Cudney (2011) and Sharma et al. (2007). As can be seen from the Table 2, the LTB case has more complexity than other two cases. The same formula for all three types of quality characteristics with more simplicity in relevant formulation has been proposed (Sharma et al., 2007). Their proposed formula is based on the lack of accessing target to infinity for LTB case, because it is unachievable. The proposed formulation could be replaced by all three types of expected quality loss mentioned in below:

$$
Q=C_{0}\left[\mu^{2}(1-\alpha)+\sigma^{2}\right]
$$

while in Eq. (2), $\alpha$ is equal to $\frac{T}{\mu}$ when $0 \leq \alpha \leq m$ and $m$ is a large number. The amount of $\alpha$ could be defined by decision maker and $T$ is a target point for quality characteristic. For different values of $\alpha$ the expected loss represents different expected losses for each type of NTB, LTB, or STB. This value shows the shifting of $\mu$ to right or left side of target point and can be chosen zero for STB type, a large number more than one is considered for LTB type and also 1 for NTB. But, it is strongly recommended that the target point and specially $\alpha$ it does not need to be a large number or infinity for LTB cases, but it just needs to be significantly greater than one. It has recommended by Sharma et al. (2007) and Sharma and Cudney (2011) that in the case of LTB the magnitude of $\alpha$ needs to significantly greater than one but not necessarily a large number or infinity, and they suggested $\alpha=2$ as an appropriate number to be employed in practice.

\subsubsection{Classification of Factors and Data Types}

In robust design approach, two types of factors can be treated for experiments, fixed and random types, as depicted in Fig. 6. When the factor levels are technically controllable, it means these factors are 'fixed'. In addition, levels in this type of factor can be reexamined and reproduced. 'Random' factors are not technically controllable. Each level does not have technically meaning, and typically levels of a random factor cannot be reexamined and reproduced. 


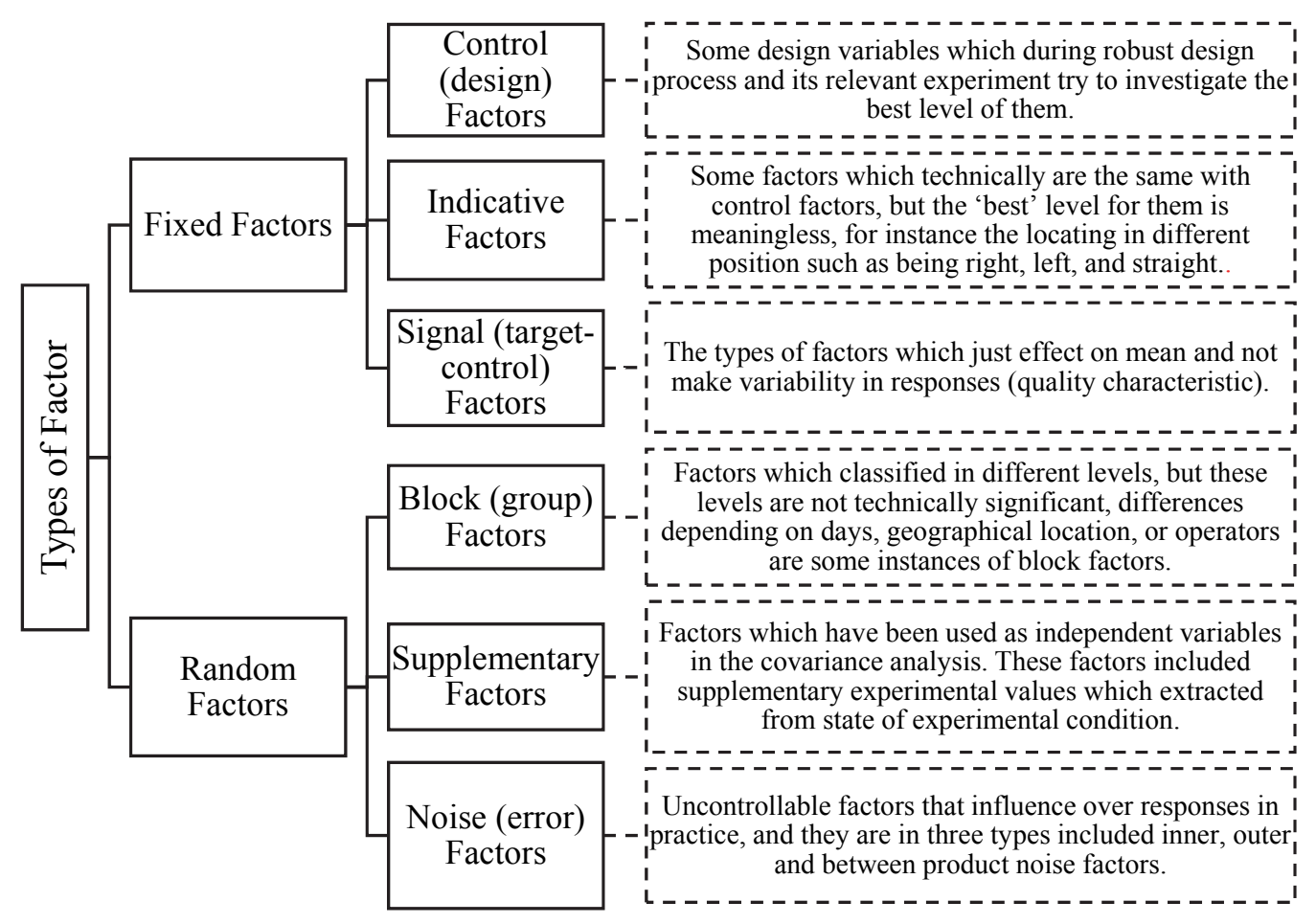

Fig. 6. Different types of factors which influence process in practice

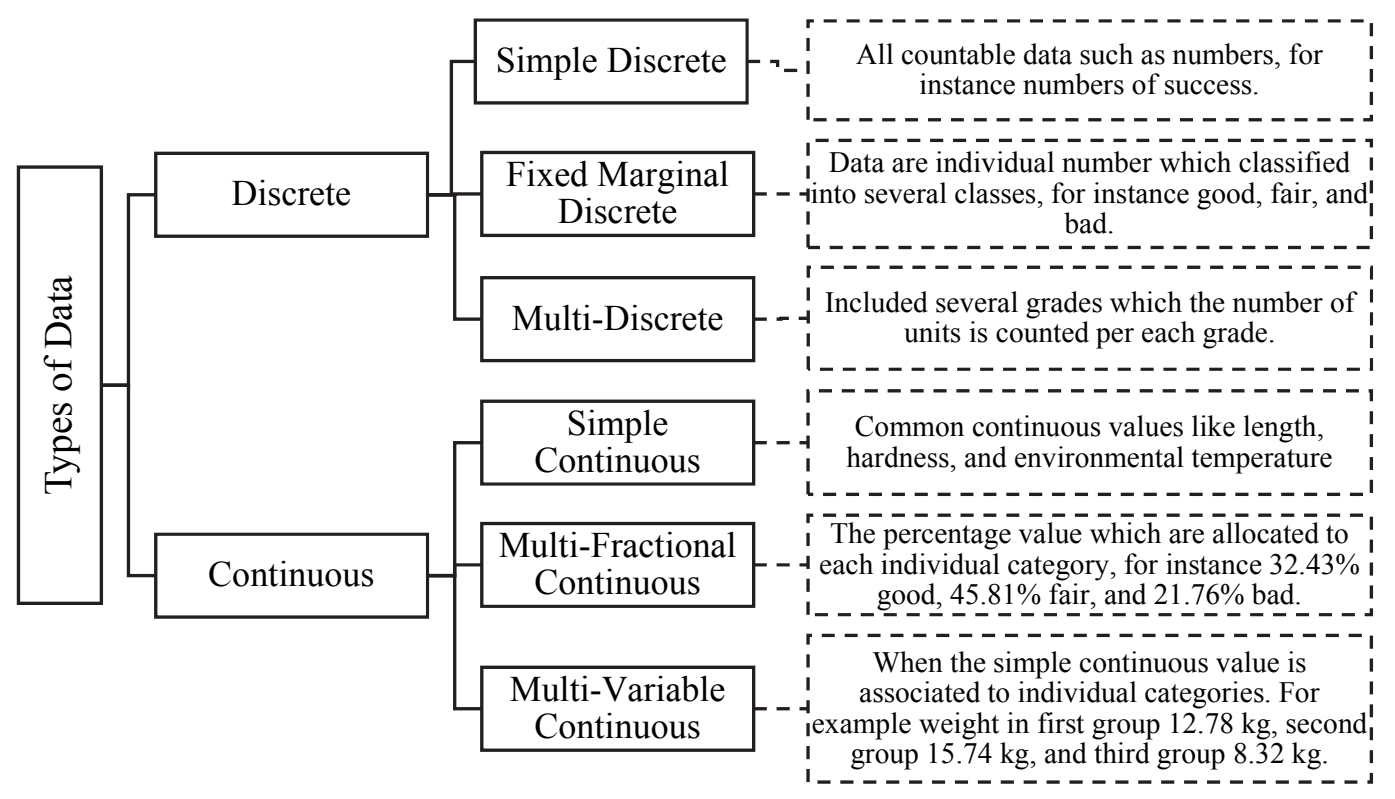

Fig. 7. Types of data based on Taguchi approach

Data in the experimental environment are usually divided into two different types of discrete and continuous. Taguchi has divided each of both types into three classes, as illustrated in Fig. 7 (Park 1996; Park \& Antony, 2008). 
This classification plays an important role in deciding about a number of necessity replications for experiments and determines the best method for analyzing data. In practice, the most process has been interfaced by a different combination of factors and data types, so it is important to consider them in robust design problem and define the robust optimization model. The survey in the literature revealed most studies have neglected to attend this importance for proposing comprehensive robust optimization method which can cover variety combination of factors with different types of data.

\subsubsection{Dual Response Surface Method}

Some authors like Myers et al. (2016) and Lin and Tu (1995) proposed to make a model based on separate process components included the mean and the variance. This methodology is adopted the so-called dual response surface approach. This model has employed a response surface for the process mean and another response surface for the process variance separately. This kind of model has been employed a type of design of sample point with a combination of both control and noise factors which is named combined array design. By combining both types of factors in process included design and noise factors, we can approximate the $y=f(X, Z)$ as a function of $m$ number of design factors $(X)$ and $n$ number of uncertainties set $(Z)$. If we consider $(W)$ as a vector, which includes both sets of design and noise factors $(w=m+n)$ then the mean and variance of each response (quality characteristic) based on the second order term of Taylor series by expanding $y$ around $E(y)$ could be computed separately as follows,

$$
\begin{aligned}
& E(y)=f(W)+\frac{1}{2} \sum_{i=1}^{w} \sum_{p=1}^{w} \frac{\partial^{2} f(W)}{\partial x_{i} \partial x_{p}} \cdot \Delta_{i p} \\
& V(y)=\sum_{i=1}^{w} \sum_{p=1}^{w} \frac{\partial f(W)}{\partial x_{i}} \cdot \frac{\partial f(W)}{\partial x_{p}} \cdot \Delta_{i p}
\end{aligned}
$$

When $i \neq p$ the amount of $\Delta_{i p}$ depicts the covariance between $i_{t h}$ and $p_{t h}$ factors and is variance of $i_{t h}$ factor when $i=p$. Notably, there are different optimization approaches available on dual response methodology where some of them are referenced in (Ardakani \& Noorossana, 2008; Beyer \& Sendhoff, 2007; Nha et al., 2013; Yanikoglu et al., 2016), so here just for instance some common methods of them are mentioned in Table 3.

Table 3

Two methods of optimization based on dual response surface

Method (A): (bi-objective model) (Chen, W. et al., 1999) Method (B): (MSE model) (Del Castillo \& Montgomery, 1993)

Minimize: $\left[\frac{E(y)}{E(y)^{*}}, \frac{V(y)}{V(y)^{*}}\right] \quad$ Minimize: $\left(E(y)-\right.$ Target $^{2}+V(y)$

Subject to: System Constraints

Subject to: System Constraints

\subsubsection{Positive and Negative Points of View on Taguchi Approach}

Generally, despite some criticisms which would be mentioned in the following, robust design methodology has been advocated by most researchers in lots of different studies and it has been employed to improve the performance and quality of processes for various problems in the real world (Myers et al., 1990). Since Genichi Taguchi introduced his methods for off-line quality improvement in AT\&T Bell laboratories in United State during 1980 till 1982, robust design method has been used in many areas in the real world of engineering (Phadke, 1989). Myers et al. (2016) defended the vital role of noise $\times$ noise interaction in parameters design problems, and argued that the framework of these interactions defines the nature of non-homogeneity of process variance and typifies the design of parameters. The application of robust design optimization has been contributed by great researchers to quality improvement of various 
processes or product design in practice, and several appropriate studies have been reviewed the application of Taguchi methodology in real case studies, (e.g. Beyer \& Sendhoff, 2007; Dellino et al., 2015; Gabrel et al., 2014; Geletu \& Li, 2014; Park \& Lee, 2006; Wang \& Shan, 2011). In current reviewing of studies, the application of robust design methodology on optimizing the process in two types of production and project management were considered, whose results are described in section 4. On the other side about shortcomings of Taguchi's idea in designing the process with a robust framework, some criticism have been extracted from different studies. Myers et al. (1990) presented an analytical study on Taguchi method. They mentioned five different criticisms of Taguchi's approach in robust parameters design. The first one is the inefficiency of the signal to noise ratio. Second one is the shortage of ability in Taguchi design parameters to approach a flexible process modeling. The third one is the number of experiments in Taguchi robust design with their $\mathrm{SN}$ ratio that is not economical. Preoccupation with optimization is fourth, and fifth no formal allowance for sequential experimentation. The Taguchi approach with its crossed arrays and signal to noise ratios have emphasized the interaction between design variables with each other and have ignored the importance of interaction between design (control) and noise variables (Myers et al., 2016). In addition, some other drawbacks have been connected to traditional Taguchi's approach. First, in designing variables with orthogonal arrays and signal to noise ratio, the process constraint are ignored for designing parameters, and secondly robust design with Taguchi approach just deals with a single quality characteristic as a response in each run of the method. So, it could not propose the best design by considering all responses at the same time. Thirdly Taguchi method just investigates the best levels of design variables in the discrete region and could not treat in whole design ranges (Dellino et al., 2015; Park \& Lee, 2006).

\subsubsection{Robust Optimization Based on Uncertainty Scenario Sets}

While in Taguchi approach the procedure of designing variables with applying orthogonal array and signal to noise ratio has been done in discrete space, so it is impossible to investigate a wide range of design spaces. In practice, design in continuous space often is required as well. However, for the system different constraints could not be resolved by Taguchi parameter design, but in robust optimization method, the constraints under uncertainty can be easily covered (Park \& Lee, 2006). Moreover, by facing real-world optimization problems, the standard techniques of mathematical programming can be used. A great number of studies have been performed where mathematical programming can contribute to robust optimization (Beyer \& Sendhoff, 2007). Under the linear approach, we are interested in taking a suboptimal solution for the nominal values of the data in order to ensure feasibility of solution when it is near optimal. Bertsimas and Sim (2004) investigated the problem of solving linear robust optimization problems with uncertain data proposed in the early 1970s. A common structure of robust optimization under uncertainty (linear programming problem) is defined as follow:

$$
\left\{\min _{x}\left\{c^{T} x+d: A x \leq b\right\}:(c, A, b, d) \in \mathcal{U}\right\}
$$

The data $(c, A, b, d)$ varying around in a given uncertainty set $\mathcal{U}$ and $x \in \mathbb{R}^{n}$ is the vector of decision variables, $c \in \mathbb{R}^{n}$ and $d \in \mathbb{R}$ form the objective, $A$ is an $m \times n$ constraint matrix, and $b \in \mathbb{R}^{m}$ is the right hand side vector of constraint (Ben-Tal et al., 2009). In terms of stochastic optimization, we assume uncertain numerical data are random, and these random data in the simplest case follow certain probability distribution which is partially known in more setting of data. In this case the formulation is shown as below:

$$
\left\{\min _{x, t}\left\{t: \operatorname{Prob}_{(c, A, b) \sim P}\left\{c^{T} x+d \& A x \leq b\right\} \geq 1-\varepsilon\right\}\right\}
$$

where $\varepsilon$ is a number much less than one $(\varepsilon \ll 1)$ which is tolerance and $P$ is the distribution of data $(c, A, b)$ (Ben-Tal et al., 2009). Depending on the cost of optimization to be either complete or partially satisfying constraints all or part of possible uncertain scenarios would be contributed in 
optimization problem. In literature different number of robust optimization methods have been defined in process engineering where recent and comprehensive technical reviews can be found (e.g. Bertsimas et al., 2011; Beyer \& Sendhoff, 2007; Gabrel et al., 2014; Geletu \& Li, 2014). Undoubtedly, Min-Max and two-stage approach have been widely used in region of robust optimization problems (Geletu \& $\mathrm{Li}$, 2014)

\subsection{8 min max Approach}

In the worst-case scenario of uncertainties, it is assumed that all variations of system performance may occur simultaneously in the worst possible combination of uncertainties. So, with respect to the min-max approach we try to minimize the maximum variability in the process performance due to the existence of uncertainty in their worst framework. The general formulation of min-max approach is shown below:

$$
\min _{x \in X} \max _{z \in Z} f(x, z)
$$

subject to

$$
\max _{z \in Z} g_{j}(x, z) \leq 0 \quad, j=1,2, \ldots, J
$$

Since $X$ is design variables vector and $Z$ is uncertainty set. In spite of some shortcoming such as tending to be overly conservative and may not cost-effective (Yu et al., 2015), this method provides a one-step formulation with optimal design and flexibility which has been employed in most problems as a common versatile approach (Ben-Tal et al., 2009; Geletu \& Li, 2014). Furthermore, the optimization problem under uncertainty with min-max formulation expresses a problem of minimization of the worst case (maximum) influence of the uncertainties on the process performance.

\subsubsection{Two-stage Approach}

Because a solution of the single-stage robust optimization method must protect against any possible combination of uncertainty set, the single-stage tends to be excessively conservative and may not costeffective. To address such a challenge, two-stage robust optimization method has been proposed to cover problem, where decisions to be divided into two stages included before and after uncertainty is revealed (Yu \& Zeng, 2015). The first stage is that of variables that are chosen prior to the realization of the uncertain event. The second stage is the set of resource variables which illustrate the response to the firststage decision and realized uncertainty. The objective is to minimize the cost of the first-stage decision and the expected value of the second-stage recourse function. The classic two-stage stochastic program with fixed resource is (Takriti \& Ahmed, 2004):

$$
\left\{\min _{x} c x+E_{p}\{R(x, z): A x=b, x \geq 0\}\right\}
$$

The resource function $R(x, z)=\operatorname{Min}_{y}\left\{Q(z)_{y}: \Delta y=h(z)-T(z) x, y \geq 0\right\}$ shows the cost in the second stage. It is a function of the random vector of uncertainty $z$ which can variate over different set of uncertainties with a given probability distribution $P$. The vector $x$ represents the first-stage decision variable with a relevant cost of $c$ and a feasible set of $\{A x=b, x \geq 0\}$. Notably, both parameters $c$ and $h(z)$ are row representations. In the above formulation, the variable $x$ must be determined before the actual realization of the uncertain parameter, $z$. Therefore, once the variable $x$ has been decided and a random sets of uncertainty is presented, the solution of optimization problem, $y$ is determined, (See Takriti \& Ahmed, 2004) and more descriptions are carried out in (Marti, 2015). Consequently, the twostage approach compares with a regular approach like single-stage, make a solution which is less conservative and more cost-effective (Yu \& Zeng, 2015). Therefore, over the last few years, the two- 
stage formulations has been employed in the real problem as well, for instances, (See Steimel \& Engell, 2015; Zhang \& Guan, 2014).

\subsection{Robust design optimization hybrid metamodeling}

Metamodeling is the analysis, construction, and development of the frames, rules, constraints, models and theories applicable and useful for modeling a predefined class of problems. Computation-intensive of design problems is becoming increasingly common in manufacturing industries. To address such a challenge, approximation or metamodeling techniques are often used. Metamodeling techniques have been developed from many different disciplines including statistics, mathematics, computer science, and various engineering disciplines (Wang \& Shan, 2007). Furthermore, Metamodeling techniques have been used to avoid intensive computational and numerical simulation models, which might squander time and resource for estimating model's parameters. Metamodeling has utilized variety statistical and mathematical approach to interpreting parameters and their relationship in original models. If input or design variables $(x)$ and responses or outputs $(y)$ have a relationship as $y=f(x)$ then a model of the model or meta-model which approximate the relationship is $\hat{y}=g(x)$ and $\hat{y}=y+\varepsilon$ where $\varepsilon$ represents an error of approximation (Simpson et al., 2001). Some simulation optimization methods have been introduced by Anderson et al., (2015) and Carson \& Maria (1997). Metamodeling methods have been greatly applied in engineering design when the problem is computationally expensive and needs to be improved by more flexibility in the model (Jin, R. et al., 2003). There are different number of methods which have been introduced as meta-models to approximate the relationship between response and design variables of process, and they can be found in several comprehensive technical surveys in literature. In addition, Investigating in literature shows that two versatile methods, RSM and Kriging, have been applied more in different optimization problems in the real world (See Dellino et al., 2015; Jin et al., 2003; Simpson et al., 2001; Wang \& Shan, 2007).

\subsubsection{Classification of Experimental Design}

The design of experiments (DOE) methodology plays an important role in the construction of a metamodel by proposing a limited number of experiments as much as possible (Kartal-Koç et al., 2012).

\section{Factorial Design}

- Included all possible factor combinations, while the order of this combination is completely random. Some methods such as single-factor, two-factor, $2^{\mathrm{k}}$ and $3^{\mathrm{k}}$ factorial design

\section{Fractional Factorial Design}

- When the cost and time of experiments are important to control, so the fraction of all possible factor combinations can be used, while the order of this combination is completely random. Some methods such as orthogonal arrays, Placket-Burman design, Latin square designs, and Graeco-Latin square designs. and Nested Design

- All possible factor combinations are considered, but some restriction is imposed on order of combination and not randomize.

\section{Incomplete Block Design}

-When running of all combinations in each block cannot be run because of inadequate experimental facilities.

\section{Response Surface Design and Mixture Design}

-When the objective is to estimate a regression model to find a functional relationship between design factors (independent variables) and response (dependent variable). Some methods such as central composite design (CCD), rotatable design, simplex designs, mixture designs, and evolutionary operation design are belonged to this class.

Fig. 8. Classification of experimental design 
The science of experimental design included some integrated techniques is used to increase the efficiency of obtained information and analyzing them. The basic principles of DOE includes factorial design and analysis of variance (ANOVA) was first introduced by Fisher in the 1920s in England and was presented in his book in 1935 as the first book on experimental design, (See Park \& Antony, 2008). Shortly after, the concept of DOE was employed by a great numbers of engineers to improve different processes performance in the real world, and today there are a number of studies which have developed the traditional concept of DOE, see (Myers et al., 2016; Park, 1996; Park \& Antony, 2008) and recent study (Kartal-Koç et al., 2012). There are various types of experimental designs which determine strategies to locate needs sample points in design region in such way to achieve at least variance. Park and Antony (2008) classified the experimental designs based on different factor combinations and the amount of randomization of experiments, which illustrates in Fig. 8.

\subsubsection{Response Surface Design (RSM)}

Because of the variance in the objective function, robust optimization has needed second-order derivatives against nonlinear programming. Though both nonlinear programmings with second-order derivatives could be used in problem (Park \& Lee, 2006). Nowadays, the application of the Response Surface Methodology (RSM) is being significantly increased. The RSM has been used for approximation and more investigation robustness in robust design approach. The response surface methodology based on polynomial regression has been widely applied in engineering design. Different statistical and mathematical techniques have been used in RSM for developing, improving, and optimizing the process. The expression of the second-order response surface model is shown as below framework:

$$
y=f(X)=\hat{\beta}_{0}+\sum_{i=1}^{m} \hat{\beta}_{i} x_{i}+\sum_{i=1}^{m} \hat{\beta}_{i i} x_{i}^{2}+\sum_{i=1}^{m} \sum_{p=1}^{m} \hat{\beta}_{i p} x_{i} x_{p}+\varepsilon,(i<p=2),
$$

where $\widehat{\beta}_{0}, \hat{\beta}_{i}$ and $\hat{\beta}_{i p}$ are unknown regression coefficients and the term $\varepsilon$ is the usual random error (noise) component (Myers et al., 2016). The functional purposes of RSM which are found in literature can be mentioned as below:

1- Approximate the relationship between design (dependent) variables and single or multi-response (independent variables).

2- Investigating and determining the best operating condition for the process, by finding the best levels of design region which can satisfy operating limits.

3- Implementing robustness in quality characteristics of the process by finding robust designing in the process.

\subsubsection{Kriging}

Since Krige (1951) addressed the geostatistics, today Kriging models have been used as a widespread global approximation technique (Jurecka, 2007). Kriging is an interpolation method which could cover deterministic data, and it is highly flexible due to ability in employing a various range of correlation functions. The higher accuracy of Kriging models than the other alternatives such as response surface modeling are confirmed in the literature (Dellino et al., 2015; Simpson et al., 2001). In a Kriging model, a combination of a polynomial model and realization of a stationary point are assumed by the form of:

$$
y=f(X)+Z(X)+\varepsilon
$$

where $f(X)=\sum_{j=0}^{k} \hat{\beta}_{j} f_{j}(X)$, and the polynomial terms of $f_{j}(X)$ are typically first or second order response surface approach and coefficients $\widehat{\beta}_{j}$ are regression parameters $(j=0,1, \ldots, k)$. The term $\varepsilon$ describes approximation error, and the term $Z(X)$ represents realization of a stochastic process, which 
most time normally distributed Gaussian random process with zero mean, variance $\sigma^{2}$ and non-zero covariance. The correlation function of $Z(X)$ is defined by:

$$
\operatorname{Cov}\left[Z\left(x_{i}\right), Z\left(x_{p}\right)\right]=\sigma^{2} R\left(x_{i}, x_{p}\right)
$$

where $\sigma^{2}$ is the process variance and $R\left(x_{i}, x_{p}\right)$ is the correlation function, and can be chosen from different functions proposed in the literature. Due to tuning the correlation function with sample data, the Kriging is extremely flexible to capture nonlinear treatment of model (Jin et al., 2003). Among literature, some studies have been found which sufficiently describe Kriging metamodel methodology, (Dellino, 2015; Jin et al., 2003; Jurecka, 2007; Simpson et al., 2001).

\subsubsection{Evaluating Metamodels}

There are number of indexes to evaluate metamodel accuracy, see (Cao et al., 2015; Dellino et al., 2009; Jin et al., 2003; Wang \& Shan, 2007).

Table 4

Metamodels measurement metrics

\begin{tabular}{ccc}
\hline Index & Type & Equation \\
\hline $\mathrm{R}^{2}$ & Smaller number is better & $R^{2}=1-\frac{\sum_{j=1}^{k}\left(y_{j}-\widehat{y_{j}}\right)^{2}}{\sum_{j=1}^{k}\left(y_{j}-\overline{y_{j}}\right)^{2}}$ \\
RAAE & Larger number is better & $R A A E=\frac{\sum_{j=1}^{k}\left|y_{j}-\widehat{y}_{j}\right|}{m \cdot \sqrt{\sum_{j=1}^{k}\left(y_{j}-\bar{y}_{j}\right)^{2}}}$ \\
RMAE & Larger number is better & $R M A E=\frac{\operatorname{Max}\left(\left|y_{1}-\widehat{y_{1}}\right|, \ldots,\left|y_{k}-\widehat{y_{k}}\right|\right)}{\sqrt{\sum_{j=1}^{k}\left(y_{j}-\overline{y_{j}}\right)^{2}}}$ \\
\hline
\end{tabular}

Three common methods are $R^{2}$, Relative Average Absolute Error (RAAE), and Relative Maximum Absolute Error (RMEA), which are defined in Table 4. In all equations of Table 4, $\overline{y_{j}}$ is mean of observed values $\left(y_{j}\right)$ and $\widehat{y}_{j}$ is corresponding predicted values. Also, the large number of $R$ square and small number of RAAE and RMEA is depicted more accuracy in metamodel.

\subsection{Multi-objective robust optimization}

In practice, the designer often has to deal with problems that involve conflicting objectives and source of uncertainty. The prospering in methods of Multi-Objective Robust Optimization (MORO) could be divided into previous and recent studies. Previously, robust design approach has been combined with some different methods in multi-objective optimization such as the weighted sum method (Zadeh, 1963), goal programming (Charnes \& Cooper, 1977), physical programming (Messac \& Ismail-Yahaya, 2002), compromise programming (Chen et al., 1999), desirability function (Costa et al., 2011) and $\mathrm{L}_{\mathrm{p}}$ metrics methods (Miettinen, 2012). Recently, some developed methods have been proposed as evolutionary algorithms such as simulated annealing (Suman \& Kumar, 2006), particle swarm optimization (Parsopoulos \& Vrahatis, 2002) and non-dominated sorting genetic algorithm (Deb et al., 2002), and Non-dominated Sorting Genetic Algorithm II (NSGA-II) (Martınez-Frutos \& Marti-Montrull, 2012).

In the process optimization, a common problem is to determine optimal operating condition that makes the best balance among the multiple quality characteristics of a product. In the real situation of the process, difficulties arise because of different units of measurement, criteria, and levels of importance among the multiple objectives or quality measurements. Moreover, different methods have been presented which attempt to tackle the problem of optimizing multiple objectives simultaneously, (See Marler \& Arora, 2004). In addition, some common and uncomplicated methods which have been 
employed in the most multi-objective problem are the desirability function (Chen et al., 2011), an evolutionary algorithm (Deb, 2011), and different metrics methods (Hwang \& Masud, 2012). The weighted $\mathrm{L}_{\mathrm{p}}$ metric method could be applied in the robust multi-objective to find a Pareto optimal solution, (See Ardakani \& Noorossana, 2008). The $\mathrm{L}_{p}$ metric is used to measure the distance between objectives (responses) of the process and the relevant target points. The overall function to integrate all responses with Lp metric method used Eq. (12):

$$
U=\left(\sum_{k=1}^{K} w_{k}\left|f_{k}(X)-\overline{\overline{f_{k}(X)}}\right|^{p}\right)^{\frac{1}{p}}
$$

Since $\overline{\overline{f_{k}(X)}}$ is the ideal point for $k_{t h}$ response and the quantity of $w_{k}$ shows the importance of $k_{t h}$ response compared to others and can take a value between zero and one, so that $\sum_{k=1}^{K} w_{k}=1$ and assigned by the decision maker. The value of $p$ while $1 \leq p \leq \infty$ indicates the emphasizing on deviation of each function from the target point. As a general, the cases of $p=1,2, \ldots, \infty$ is more common to employ in computational models, (See Miettinen, 2012). Notable in above, all responses must have the same scales in the formulation. When responses do not have the same scale, each response could be scale less by applying Eq. (13):

$$
U=\left(\sum_{k=1}^{K} w_{k}\left|\frac{f_{k}(X)-\overline{f_{k}(X)}}{\overline{f_{k}(X)}-\overline{f_{k}(X)}}\right|^{p}\right)^{\frac{1}{p}}
$$

Here $\overline{f_{k}(X)}$ is the worst value which can be allocated to $k_{t h}$ response in design variables region of $(X)$ (Ardakani \& Noorossana, 2008; Miettinen, 2012). In the aforementioned method, the correlation between responses (quality characteristics) is ignored, and independence between them is assumed. In practice the variance of each quality characteristic is not constant over the experimental space. Under such condition, the multi-response model must be able to consider the correlation among quality characteristic. A number of recent studies which have been attended variance-covariance framework of responses are Cheng et al. (2013), Rathod et al. (2013), Romano et al. (2004) and Salmasnia et al. (2013).

\subsection{Dynamic Problems (Robust Optimization over Time)}

In real-word problems, most optimization problems, often have faced to various changing in their environment. In an optimization problem, each change in condition can involve variation in the problem components such as objective functions, design variables, environmental or noise factors as well as constraints. The number of problem components (objectives, design variables, and constraints) might vary over time during the optimization. For instance, in the social problem, the population size is such a dynamic factor which change from time to time (Jin et al., 2013). To address such a challenge, the Dynamic Optimization Problems (DOPs)(Fu et al., 2015) have been employed to propose robust optimal solution over time. So the existing static models have to be revised to dynamic approach in uncertainty environment as Robust Optimization Over Time (ROOT) (Beyer \& Sendhoff, 2007; Jin et al., 2013). However, few studies have been concerned with optimizing the robust design optimization over time involving static and dynamic components, see (Fu et al., 2015; Jin \& Branke, 2005; Wu \& Yeh, 2009; $\mathrm{Wu}, 2015)$.

\subsection{Multi-Process System}

Nowadays, by increasing competition among all relevant companies in specific product around the world to attract national or international customers, many of them have used some engineering methodology for finding enough ability to provide customer's satisfactions. For more flexibility, it is important to attend all interacted processes in the system as a multi-process environment. In practice, a system consists of several interacted processes (multi-process) which have complex interaction to each other and 
continue in the direction of distinct system objectives, as shown in Fig. 9. The optimization model must be able to handle a trade-off between the best performance from all processes and system cost. Different types of uncertainty and noise factors, and also changeability in goals over time can influence on each process separately in a multi-process environment. Moreover, optimization methods need to be developed for optimizing all interacted process in a multi-process situation as well as optimizing one process at the same time (Bertsekas, 1998). So, among reviewing articles, extending proposed robust optimization methods into the multi-process environment was considered, which the results are shown in section 4.

\subsection{Production and Project Management under Uncertainty}

In practice, as well as various problems in engineering processes and systems, management methodologies could be affected by uncertain parameters which create deviance between the result of optimization model with the target. Proposing a robustness designs for these types of problem are purposes of most studies which have been employed robust design optimization approach. Developing traditional methods under uncertain and noisy conditions into two main methodologies of management science such as production management and project management have been considered in studies. Production planning, job shop, and flow shop scheduling in production management and project scheduling with a trade-off between time, cost and quality are some important problems in both methodologies of production and project management. Robust optimization methods attempt to model production planning problem in such a way to minimize cost, wastage, and effect of uncertainties or risk and also maximize the total expected profit (Ait-Alla et al., 2014). Among literature, in production management methodology, two main problems included first robust production planning, (See Ait-Alla et al., 2014; Asih \& Chong, 2015; Gyulai et al., 2015; Khademi Zare et al., 2006; Mirzapour Al-e-Hashem et al., 2011) and comprehensive review study (Mula et al., 2006) and second robust supply chain (for example see (An \& Ouyang, 2016; Hasani \& Khosrojerdi, 2016; Pishvaee \& Torabi, 2010; Pishvaee et al., 2011, 2012) under uncertain condition which has been more considered than other relevant parts.

In real word delivering projects on time within certain budget by covering all needed project specifications, still seems extremely difficult (Demeulemeester \& Herroelen, 2011). The majority of previous relevant studies just have concentrated to schedule project in the certain and deterministic

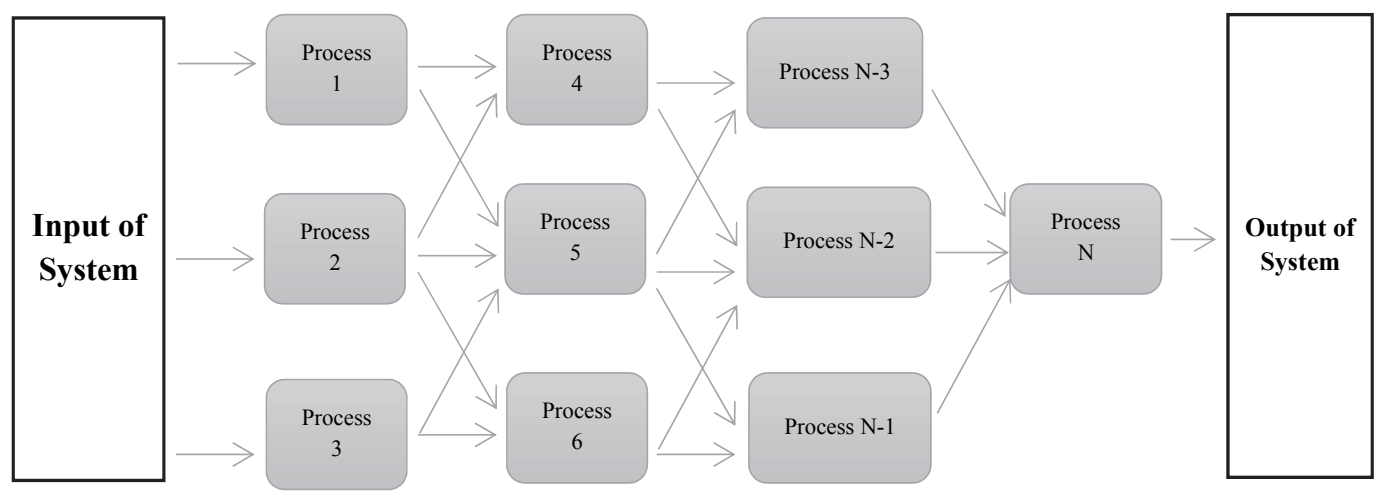

Fig. 9. A general overview of multi-process system

environments, in spite of the existence of various types of uncertainties in project conditions, such as uncertainty in activity duration, predecessors, and resources (human, machine, budget). Project are often faced with various types of uncertainties that have a negative influence on project components such as activity duration and costs. So it is crucial to modify effective methods to a robust schedule of the project which is less sensitive to the variability of uncontrollable factors (Hazir et al., 2010). Herroelen and Leus (2004) and (2005) in two different comprehensive review papers have tried to investigate the methods of reactive and proactive scheduling project under uncertain conditions. In addition, recent survey on scheduling problems based on time and cost can be found in (Allahverdi, 2015). 


\section{Discussion and results}

All selected articles were systematically analyzed included in-depth review, evaluate and interpret of each article methodologies of research. Relevant information was extracted to a predefined database.

\subsection{Methodologies}

Throughout the literature review, several important methods were investigated in selected articles, which are separately classified as following. Note that in continuing definition of each class, the term of "problem" is a contraction of robust design optimization for the process by considering uncertainty or noise factors.

M.1: Articles which have employed the classic concepts of robust design such as Taguchi parameters design with orthogonal arrays, signal to noise ratio or quality loss function approach to improving product and process.

M.2: The method of mathematical programming in both approaches of robust design optimization included Taguchi approach and scenario sets have been used by articles in this class.

M.3: Multi-objective problems and relevant methods have been attended by this class's articles for problems under uncertainty.

M.4: Metamodels methodology were contributed by robust design optimization for the designing process under uncertainty with minimum computational complexity.

M.5: In problem environment, the fuzzy approach has been considered in facing by uncertainties.

M.6: The distinct strategy in conflicting with uncertainty or noise factors in problem have been proposed.

M.7: The proposed methods by articles in this class are able to extend and generalized in some other process optimization problem, and not limited to specific condition or location of the problem.

M.8: The computational complexity and time consuming to solve the relevant problem have been considered.

M.9: The process cost next to the process performance has been kept as problem objectives. It means proposed optimization method has been able to handle a trade-off between cost and performance.

M.10: Multi-process environment as a system (Fig. 9) which consists of several interlinked processes have been considered in the problem by selected articles in this class. Notably, some studies in this class just consider the concept of network in their studies where their approaches have been able to accommodate into multi-process systems and not attended the concept of multi-process directly. The trade-off between the best performance of all processes and the total cost is the main purpose of optimization in the multi-process system.

M.11: The uncertainty in physical constraints have been considered as well as the objectives to optimize process and find global robustness solution.

M.12: Articles in this class have attended dynamic optimization method over time for their problem.

M.13: Different combinations of data included discrete and continuous data (Fig. 7) have been handled by proposed method.

M.14: The proposed method have been able to consider different probability distributions in the process for design or noise variables, in stochastic programming, or method is distribution free.

\subsection{Analysis and interpreting}

Based on predefined classes in objective and methodologies of each article, the identifying and findings of results are reported in Tables 5. 


\subsection{Discussion}

To analyze the results in Table 6, we consider the proportion of articles in both groups of objective and methodology. Fig. 10 illustrates the proportion of articles (total 150 articles) in each class of methodology. Consequently, as can be seen from the figure and also by a systematic review of selected articles, several important points are concluded as the findings of this study. In addition to the selected articles, a brief glance of almost other relevant literature could demonstrate the mentioned points.

1- To the best of our knowledge, there are not adequate cases in literature that compare different methods of metamodeling faced with robust optimization models for the real problem in practice with uncertain and noise parameters. The various methods of metamodeling have never compared to each other about where metamodel is definitely superior to others according to real circumstances of the problem (Beyer \& Sendhoff, 2007; Jin, et al., 2001; Jurecka, 2007; Wang \& Shan, 2007). In optimizing the process, by attending uncertainty, multi-objectives, and dynamic parameters over time the computational complexity increase more and more, since metamodels could reduce computational time and cost consuming, see (Ateme-Nguema et al., 2012).

2- In multi-objective optimization problems, metamodels could be used to reach an approximation of an overall objective function, but their relevant application is not straightforward as well as classical, evolutionary, or meta-heuristic algorithms (Dellino et al., 2009).

3- The trade-off between time, cost and quality has not been extensively done in the literature yet for problems under uncertainty (Salmasnia et al., 2012). This subject is vital for appropriate scheduling of projects in practice.

4- In the case of dynamic programming over time, few models could be found were mainly theoretical particularly in problems under different types of uncertainty et al., 2009; Wu, 2015). For instance in robust design problems, most models did not pay much attention to the time value of money for quality loss and product degradation over time (Peng et al., 2008).

5- To the best of our knowledge, there are no considerable works on proposing methods which cover different types of data mentioned in Fig. 7 (discrete and continues data for design variables and also noise factor), in spite of importance function of these types of data with different combination in practice (Bertsimas \& Sim, 2004).

6- In practice, most systems consist of several interacted processes by intensive linking to each other. Optimizing a multi-process environment under noise and uncertain uncontrollable parameters have not been considered as well as a single process problem. Most of the times, the results which are obtained separately for each single process, could not be expanded for the whole system, while it needs trade-off between results.

One of the other problems that has been mentioned by some studies for process optimization problem, is the long distance between producing knowledge in the academic levels with real requirements of industries in practice. This gap has also existed in optimization models as well as another field of engineering (Ehrgott et al., 2014; Gabrel et al., 2014; Goerigk \& Schöbel, 2015; Wang \& Shan, 2007). 
Table 5

Findings of review articles based on objective and methodology

\begin{tabular}{|c|c|c|c|c|c|c|c|c|c|c|c|c|c|c|c|}
\hline \multirow{2}{*}{ No } & \multirow{2}{*}{ Ref. } & \multicolumn{14}{|c|}{ Methodology } \\
\hline & & M.1 & M.2 & M.3 & M.4 & M.5 & M.6 & M.7 & M. 8 & M. 9 & M.10 & M.11 & M.12 & M.13 & M.14 \\
\hline 1 & (Huang et al., 2016) & & $\sqrt{ }$ & & & & & & & & & & & & \\
\hline 2 & (Kokkinos \& Papadopoulos, 2016) & & $\sqrt{ }$ & $\sqrt{ }$ & & & $\sqrt{ }$ & $\sqrt{ }$ & $\sqrt{ }$ & $\sqrt{ }$ & & $\sqrt{ }$ & & & $\sqrt{ }$ \\
\hline 3 & (Wu et al., 2016) & & $\sqrt{ }$ & & & & $\sqrt{ }$ & & $\sqrt{ }$ & & & & & & \\
\hline 4 & (Kuhn et al., 2016) & & $\sqrt{ }$ & $\sqrt{ }$ & & & $\sqrt{ }$ & $\sqrt{ }$ & & & & & & & \\
\hline 5 & (Salmasnia et al., 2016) & & $\sqrt{ }$ & $\sqrt{ }$ & & & $\sqrt{ }$ & & $\sqrt{ }$ & $\sqrt{ }$ & & & & & \\
\hline 6 & (Ide \& Schobel, 2016) & & & $\sqrt{ }$ & & & $\sqrt{ }$ & $\sqrt{ }$ & & $\sqrt{ }$ & & $\sqrt{ }$ & & & \\
\hline 7 & (Zhang \& Lu, 2016) & $\sqrt{ }$ & & & $\sqrt{ }$ & & & $\sqrt{ }$ & $\sqrt{ }$ & & & & & & \\
\hline 8 & (Grossmann et al., 2016) & & $\sqrt{ }$ & & & & $\sqrt{ }$ & & $\sqrt{ }$ & & & $\sqrt{ }$ & & & \\
\hline 9 & (Wang et al., 2016) & & $\sqrt{ }$ & $\sqrt{ }$ & & & $\sqrt{ }$ & $\sqrt{ }$ & $\sqrt{ }$ & & & $\sqrt{ }$ & & & \\
\hline 10 & (Kolluri et al., 2016) & & $\sqrt{ }$ & $\sqrt{ }$ & & $\sqrt{ }$ & $\sqrt{ }$ & & $\sqrt{ }$ & $\sqrt{ }$ & & $\sqrt{ }$ & & & \\
\hline 11 & (Tsai \& Liukkonen, 2016) & $\sqrt{ }$ & & & $\sqrt{ }$ & $\sqrt{ }$ & & & $\sqrt{ }$ & $\sqrt{ }$ & & $\sqrt{ }$ & & & \\
\hline 12 & (Zhang et al., 2016) & & $\sqrt{ }$ & 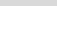 & & $\sqrt{ }$ & 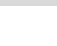 & $\sqrt{ }$ & $\sqrt{ }$ & & & $\sqrt{ }$ & & & \\
\hline 13 & (Talaei et al., 2016) & & $\sqrt{ }$ & 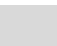 & & $\sqrt{ }$ & $\sqrt{ }$ & & $\sqrt{ }$ & $\sqrt{ }$ & & $\sqrt{ }$ & & & \\
\hline 14 & (Palacios et al., 2016) & & $\sqrt{ }$ & $\sqrt{ }$ & & $\sqrt{ }$ & $\sqrt{ }$ & & $\sqrt{ }$ & $\sqrt{ }$ & & $\sqrt{ }$ & & & \\
\hline 15 & (Ghodratnama et al., 2015) & & $\sqrt{ }$ & $\sqrt{ }$ & & $\sqrt{ }$ & $\sqrt{ }$ & & 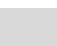 & $\sqrt{ }$ & & $\sqrt{ }$ & & & \\
\hline 16 & (Pishvaee \& Fazli Khalaf, 2016) & & $\sqrt{ }$ & & & $\sqrt{ }$ & $\sqrt{ }$ & $\sqrt{ }$ & & $\sqrt{ }$ & & $\sqrt{ }$ & & & \\
\hline 17 & (Wu et al., 2016) & & $\sqrt{ }$ & 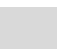 & & $\sqrt{ }$ & $\sqrt{ }$ & & $\sqrt{ }$ & & & $\sqrt{ }$ & & & \\
\hline 18 & (Zhang et al., 2016) & & $\sqrt{ }$ & 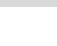 & & 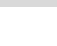 & $\sqrt{ }$ & & $\sqrt{ }$ & $\sqrt{ }$ & & $\sqrt{ }$ & $\sqrt{ }$ & & \\
\hline 19 & (Namazian \& Yakhchali, & & $\sqrt{ }$ & $\sqrt{ }$ & & $\sqrt{ }$ & $\sqrt{ }$ & & $\sqrt{ }$ & $\sqrt{ }$ & & $\sqrt{ }$ & & & \\
\hline 20 & (Wu et al., 2016) & & $\sqrt{ }$ & & & & $\sqrt{ }$ & & $\sqrt{ }$ & & & $\sqrt{ }$ & $\sqrt{ }$ & & \\
\hline 21 & (Tabrizi \& Ghaderi, 2016) & $\sqrt{ }$ & $\sqrt{ }$ & $\sqrt{ }$ & & & $\sqrt{ }$ & & & $\sqrt{ }$ & & $\sqrt{ }$ & & & \\
\hline 22 & (Aalaei \& Davoudpour, 2017) & & $\sqrt{ }$ & & & & $\sqrt{ }$ & & & $\sqrt{ }$ & & $\sqrt{ }$ & & & \\
\hline 23 & (An \& Ouyang, 2016) & & $\sqrt{ }$ & & & & $\sqrt{ }$ & & & $\sqrt{ }$ & & $\sqrt{ }$ & & & \\
\hline 24 & (An et al., 2016) & $\sqrt{ }$ & & & & & & & $\sqrt{ }$ & & & & & & \\
\hline 25 & (Cai et al., 2016) & & $\sqrt{ }$ & $\sqrt{ }$ & & 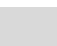 & $\sqrt{ }$ & $\sqrt{ }$ & & $\sqrt{ }$ & & $\sqrt{ }$ & $\sqrt{ }$ & & \\
\hline 26 & (Gang et al., 2015) & & $\sqrt{ }$ & & & & $\sqrt{ }$ & & & $\sqrt{ }$ & & $\sqrt{ }$ & & & \\
\hline 27 & (Lersteau et al., 2016) & & $\sqrt{ }$ & & & & $\sqrt{ }$ & & & & $\sqrt{ }$ & $\sqrt{ }$ & & & \\
\hline 28 & (Mirmajlesi \& Shafaei, 2016) & & $\sqrt{ }$ & & & & $\sqrt{ }$ & & & $\sqrt{ }$ & & $\sqrt{ }$ & & & \\
\hline 29 & (Modarres \& Izadpanahi, & & $\sqrt{ }$ & & & & $\sqrt{ }$ & & & $\sqrt{ }$ & & $\sqrt{ }$ & & & $\sqrt{ }$ \\
\hline 30 & (Ling et al., 2017) & & $\sqrt{ }$ & & & & $\sqrt{ }$ & $\sqrt{ }$ & & & & $\sqrt{ }$ & & & \\
\hline 31 & (Peri, 2016) & & $\sqrt{ }$ & & & & $\sqrt{ }$ & & & $\sqrt{ }$ & & $\sqrt{ }$ & & $\sqrt{ }$ & $\sqrt{ }$ \\
\hline 32 & (Gul \& Zoubir, 2017) & & $\sqrt{ }$ & & & & $\sqrt{ }$ & $\sqrt{ }$ & & & & & & & \\
\hline 33 & (Goerigk \& Schöbel, 2015) & & $\sqrt{ }$ & & & & $\sqrt{ }$ & $\sqrt{ }$ & $\sqrt{ }$ & & & $\sqrt{ }$ & & & \\
\hline 34 & (Gorissen, 2015) & & $\sqrt{ }$ & & & & $\sqrt{ }$ & $\sqrt{ }$ & & $\sqrt{ }$ & $\sqrt{ }$ & $\sqrt{ }$ & & & \\
\hline 35 & (Liu et al., 2015) & $\sqrt{ }$ & $\sqrt{ }$ & & & & 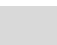 & $\sqrt{ }$ & $\sqrt{ }$ & & & & & & \\
\hline 36 & (Sun et al., 2015) & $\sqrt{ }$ & $\sqrt{ }$ & & & & $\sqrt{ }$ & & & & & & & & \\
\hline 37 & (Fu et al., 2015) & & $\sqrt{ }$ & & & & & $\sqrt{ }$ & $\sqrt{ }$ & & & & $\sqrt{ }$ & & \\
\hline 38 & $(\mathrm{Wu}, 2015)$ & $\sqrt{ }$ & & & & & $\sqrt{ }$ & $\sqrt{ }$ & $\sqrt{ }$ & & & & $\sqrt{ }$ & & \\
\hline 39 & (Khan et al., 2015) & $\sqrt{ }$ & & & & & $\sqrt{ }$ & & & $\sqrt{ }$ & & & & & \\
\hline 40 & (Park, 2016) & $\sqrt{ }$ & & & & & & $\sqrt{ }$ & $\sqrt{ }$ & & & & & & \\
\hline 41 & (Goberna et al., 2015) & & $\sqrt{ }$ & $\sqrt{ }$ & & & $\sqrt{ }$ & $\sqrt{ }$ & & & & & & & \\
\hline 42 & (Wang, 2015) & & $\sqrt{ }$ & $\sqrt{ }$ & & & $\sqrt{ }$ & & & & & & & & \\
\hline 43 & (Wang \& Pedrycz, 2015) & & $\sqrt{ }$ & & & $\sqrt{ }$ & $\sqrt{ }$ & $\sqrt{ }$ & & & $\sqrt{ }$ & & & & \\
\hline 44 & (Yu \& Zeng, 2015) & & $\sqrt{ }$ & & & & $\sqrt{ }$ & $\sqrt{ }$ & & & & & & & \\
\hline 45 & (Asafuddoula et al., 2015) & & $\sqrt{ }$ & $\sqrt{ }$ & & & $\sqrt{ }$ & $\sqrt{ }$ & $\sqrt{ }$ & & & $\sqrt{ }$ & & & \\
\hline 46 & (Dellino et al., 2015) & $\sqrt{ }$ & $\sqrt{ }$ & $\sqrt{ }$ & $\sqrt{ }$ & & $\sqrt{ }$ & $\sqrt{ }$ & $\sqrt{ }$ & $\sqrt{ }$ & & $\sqrt{ }$ & & & \\
\hline 47 & (Auzins et al., 2015) & & $\sqrt{ }$ & $\sqrt{ }$ & & & $\sqrt{ }$ & $\sqrt{ }$ & $\sqrt{ }$ & & & $\sqrt{ }$ & & & \\
\hline 48 & (Cao et al., 2015) & & $\sqrt{ }$ & & $\sqrt{ }$ & & $\sqrt{ }$ & $\sqrt{ }$ & $\sqrt{ }$ & & & $\sqrt{ }$ & & & \\
\hline 49 & (Ng et al., 2015) & & $\sqrt{ }$ & $\sqrt{ }$ & & $\sqrt{ }$ & $\sqrt{ }$ & & $\sqrt{ }$ & $\sqrt{ }$ & & $\sqrt{ }$ & & & \\
\hline 50 & (Allahverdi, 2015) & & & & & & & & & $\sqrt{ }$ & & $\sqrt{ }$ & & & \\
\hline
\end{tabular}


Table 5

Findings of review articles based on objective and methodology (Continued)

\begin{tabular}{|c|c|c|c|c|c|c|c|c|c|c|c|c|c|c|c|}
\hline \multirow[t]{2}{*}{ No } & \multirow[t]{2}{*}{ Ref. } & \multicolumn{14}{|c|}{ Methodology } \\
\hline & & M.1 & M.2 & M.3 & M.4 & M.5 & M.6 & M.7 & M.8 & M.9 & M.10 & M.11 & M.12 & M.13 & M.14 \\
\hline 51 & (Bossaghzadeh et al., 2015) & & $\sqrt{ }$ & $\sqrt{ }$ & & & $\sqrt{ }$ & & & $\sqrt{ }$ & & $\sqrt{ }$ & & & \\
\hline 52 & (Zhang \& Qiao, 2015) & & $\sqrt{ }$ & $\sqrt{ }$ & & & $\sqrt{ }$ & & & $\sqrt{ }$ & & $\sqrt{ }$ & & & $\sqrt{ }$ \\
\hline 53 & (Mavrotas et al., 2015) & & $\sqrt{ }$ & & $\sqrt{ }$ & & $\sqrt{ }$ & $\sqrt{ }$ & & $\sqrt{ }$ & & $\sqrt{ }$ & & & \\
\hline 54 & (Fu et al., 2015) & & $\sqrt{ }$ & $\sqrt{ }$ & & & $\sqrt{ }$ & & & $\sqrt{ }$ & & $\sqrt{ }$ & & & \\
\hline 55 & (Sahali et al., 2015) & & $\sqrt{ }$ & & $\sqrt{ }$ & & $\sqrt{ }$ & $\sqrt{ }$ & $\sqrt{ }$ & & & $\sqrt{ }$ & & & \\
\hline 56 & (Gyulai et al., 2015) & & $\sqrt{ }$ & $\sqrt{ }$ & & & $\sqrt{ }$ & $\sqrt{ }$ & & $\sqrt{ }$ & & $\sqrt{ }$ & & & \\
\hline 57 & (Gabrel et al., 2014) & & & & & & $\sqrt{ }$ & & & & & & & & \\
\hline 58 & (Ehrgott et al., 2014) & & $\sqrt{ }$ & $\sqrt{ }$ & & & $\sqrt{ }$ & $\sqrt{ }$ & $\sqrt{ }$ & $\sqrt{ }$ & & $\sqrt{ }$ & & & \\
\hline 59 & (Bandi \& Bertsimas, 2014) & & $\sqrt{ }$ & & & & $\sqrt{ }$ & & $\sqrt{ }$ & $\sqrt{ }$ & & $\sqrt{ }$ & & & \\
\hline 60 & (Celano et al., 2014) & $\sqrt{ }$ & & & & & & & & & & & & & \\
\hline 61 & (Geletu \& Li, 2014) & & & & & & $\sqrt{ }$ & $\sqrt{ }$ & $\sqrt{ }$ & $\sqrt{ }$ & & $\sqrt{ }$ & $\sqrt{ }$ & & $\sqrt{ }$ \\
\hline 62 & (Iancu \& Trichakis, 2014) & & $\sqrt{ }$ & & & & $\sqrt{ }$ & $\sqrt{ }$ & $\sqrt{ }$ & & & $\sqrt{ }$ & & & \\
\hline 63 & (Margellos et al., 2014) & & $\sqrt{ }$ & & & & $\sqrt{ }$ & $\sqrt{ }$ & $\sqrt{ }$ & & & $\sqrt{ }$ & & & $\sqrt{ }$ \\
\hline 64 & (Salomon et al., 2014) & & $\sqrt{ }$ & $\sqrt{ }$ & & & $\sqrt{ }$ & $\sqrt{ }$ & $\sqrt{ }$ & $\sqrt{ }$ & & $\sqrt{ }$ & & & \\
\hline 65 & (Ur Rehman et al., 2014) & & $\sqrt{ }$ & & $\sqrt{ }$ & & $\sqrt{ }$ & $\sqrt{ }$ & $\sqrt{ }$ & & & & & & \\
\hline 66 & (Can et al., 2014) & & & & $\sqrt{ }$ & & $\sqrt{ }$ & $\sqrt{ }$ & $\sqrt{ }$ & & & & & & \\
\hline 67 & (Oros et al., 2014) & & & & $\sqrt{ }$ & & $\sqrt{ }$ & $\sqrt{ }$ & $\sqrt{ }$ & $\sqrt{ }$ & & & & & \\
\hline 68 & (Chevalier et al., 2014) & & & & & & $\sqrt{ }$ & & & & & & & & \\
\hline 69 & (Jin et al., 2014) & & $\sqrt{ }$ & & & $\sqrt{ }$ & $\sqrt{ }$ & $\sqrt{ }$ & $\sqrt{ }$ & & & $\sqrt{ }$ & & & \\
\hline 70 & (Hao et al., 2014) & & $\sqrt{ }$ & $\sqrt{ }$ & & & $\sqrt{ }$ & & & $\sqrt{ }$ & & $\sqrt{ }$ & & & \\
\hline 71 & (Wu et al., 2014) & & $\sqrt{ }$ & & $\sqrt{ }$ & & $\sqrt{ }$ & $\sqrt{ }$ & $\sqrt{ }$ & $\sqrt{ }$ & & $\sqrt{ }$ & & & \\
\hline 72 & (Khaledi et al., 2014) & & & & $\sqrt{ }$ & & & $\sqrt{ }$ & $\sqrt{ }$ & & & $\sqrt{ }$ & & & \\
\hline 73 & (Dellino et al., 2012) & & $\sqrt{ }$ & & $\sqrt{ }$ & & $\sqrt{ }$ & $\sqrt{ }$ & $\sqrt{ }$ & $\sqrt{ }$ & & $\sqrt{ }$ & & & $\sqrt{ }$ \\
\hline 74 & (Ait-Alla et al., 2014) & & $\sqrt{ }$ & & & & $\sqrt{ }$ & $\sqrt{ }$ & & $\sqrt{ }$ & & $\sqrt{ }$ & & & \\
\hline 75 & (Persson \& Ölvander, 2013) & & & & $\sqrt{ }$ & & $\sqrt{ }$ & & $\sqrt{ }$ & $\sqrt{ }$ & & $\sqrt{ }$ & & & \\
\hline 76 & (Artigues et al., 2013) & & $\sqrt{ }$ & $\sqrt{ }$ & & & $\sqrt{ }$ & & & $\sqrt{ }$ & & $\sqrt{ }$ & & & \\
\hline 77 & (Gulpinar \& Pachamanova, & & $\sqrt{ }$ & & & & $\sqrt{ }$ & & & $\sqrt{ }$ & & $\sqrt{ }$ & & & \\
\hline 78 & (Zhang, Siliang et al., 2013) & & $\sqrt{ }$ & & $\sqrt{ }$ & & & 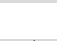 & & $\sqrt{ }$ & $\sqrt{ }$ & & & & \\
\hline 79 & (Nha et al., 2013) & & $\sqrt{ }$ & $\sqrt{ }$ & $\sqrt{ }$ & & & $\sqrt{ }$ & & & & $\sqrt{ }$ & $\sqrt{ }$ & & \\
\hline 80 & (Zhu et al., 2013) & & $\sqrt{ }$ & & $\sqrt{ }$ & & $\sqrt{ }$ & $\sqrt{ }$ & $\sqrt{ }$ & $\sqrt{ }$ & & $\sqrt{ }$ & & & \\
\hline 81 & (Salmasnia et al., 2013) & & $\sqrt{ }$ & $\sqrt{ }$ & & & & $\sqrt{ }$ & & & & & & & \\
\hline 82 & (Rathod et al., 2013) & & $\sqrt{ }$ & $\sqrt{ }$ & & & $\sqrt{ }$ & $\sqrt{ }$ & & $\sqrt{ }$ & & $\sqrt{ }$ & & & \\
\hline 83 & (Cheng et al., 2013) & & $\sqrt{ }$ & $\sqrt{ }$ & & & & $\sqrt{ }$ & & $\sqrt{ }$ & & $\sqrt{ }$ & & & \\
\hline 84 & (Dalton et al., 2013) & & $\sqrt{ }$ & & & & $\sqrt{ }$ & $\sqrt{ }$ & $\sqrt{ }$ & $\sqrt{ }$ & & $\sqrt{ }$ & & & \\
\hline 85 & (Jin et al., 2013) & & $\sqrt{ }$ & & & & $\sqrt{ }$ & $\sqrt{ }$ & $\sqrt{ }$ & $\sqrt{ }$ & & $\sqrt{ }$ & $\sqrt{ }$ & & \\
\hline 86 & (Kartal-Koç et al., 2012) & & & & $\sqrt{ }$ & & & $\sqrt{ }$ & $\sqrt{ }$ & & & & & & \\
\hline 87 & $\begin{array}{l}\text { (Martınez-Frutos \& Marti-Montrull } \\
\text { 2012) }\end{array}$ & & $\sqrt{ }$ & $\sqrt{ }$ & $\sqrt{ }$ & & $\sqrt{ }$ & $\sqrt{ }$ & $\sqrt{ }$ & & & $\sqrt{ }$ & & & \\
\hline 88 & (Pishvaee \& Razmi, 2012) & & & & & $\sqrt{ }$ & $\sqrt{ }$ & & $\sqrt{ }$ & $\sqrt{ }$ & & $\sqrt{ }$ & & & \\
\hline 89 & (Lopez Martin et al., 2012) & & & & & & $\sqrt{ }$ & & & & & & & & $\sqrt{ }$ \\
\hline 90 & (Salmasnia, Ali et al., 2012) & & $\sqrt{ }$ & $\sqrt{ }$ & & & & & $\sqrt{ }$ & $\sqrt{ }$ & & $\sqrt{ }$ & & & \\
\hline 91 & (Fu et al., 2012) & & $\sqrt{ }$ & & & & $\sqrt{ }$ & $\sqrt{ }$ & & & & $\sqrt{ }$ & $\sqrt{ }$ & & \\
\hline 92 & (Bertsimas et al., 2011) & & $\sqrt{ }$ & & & & $\sqrt{ }$ & $\sqrt{ }$ & $\sqrt{ }$ & & & $\sqrt{ }$ & & & \\
\hline 93 & (Klimek \& Lebkowski, 2011) & & & & & & $\sqrt{ }$ & & $\sqrt{ }$ & & & $\sqrt{ }$ & & & \\
\hline 94 & (Lambrechts et al., 2011) & & & & & & $\sqrt{ }$ & & $\sqrt{ }$ & & & $\sqrt{ }$ & & & \\
\hline 95 & (Sharma \& Cudney, 2011) & $\sqrt{ }$ & & & & & & $\sqrt{ }$ & $\sqrt{ }$ & & & & & & \\
\hline 96 & (Erdbrügge et al., 2011) & $\sqrt{ }$ & $\sqrt{ }$ & & & & & $\sqrt{ }$ & & $\sqrt{ }$ & & $\sqrt{ }$ & & & \\
\hline 97 & (Mirzapour Al-e-Hashem et & & $\sqrt{ }$ & $\sqrt{ }$ & & & $\sqrt{ }$ & $\sqrt{ }$ & & $\sqrt{ }$ & & $\sqrt{ }$ & & & \\
\hline 98 & (Miranda \& Castillo, 2011) & & $\sqrt{ }$ & & & & & $\sqrt{ }$ & & & & & & & \\
\hline 99 & (He et al., 2010) & & $\sqrt{ }$ & $\sqrt{ }$ & & & & $\sqrt{ }$ & $\sqrt{ }$ & & & & & & \\
\hline 100 & (Dellino et al., 2010) & & $\sqrt{ }$ & & $\sqrt{ }$ & & $\sqrt{ }$ & $\sqrt{ }$ & $\sqrt{ }$ & $\sqrt{ }$ & & $\sqrt{ }$ & & & $\sqrt{ }$ \\
\hline
\end{tabular}


Table 5

Findings of review articles based on objective and methodology (Continued)

\begin{tabular}{|c|c|c|c|c|c|c|c|c|c|c|c|c|c|c|c|}
\hline \multirow{2}{*}{ No } & \multirow{2}{*}{ Ref. } & \multicolumn{14}{|c|}{ Methodology } \\
\hline & & M.1 & M.2 & M.3 & M.4 & M.5 & M.6 & M.7 & M. 8 & M.9 & M.10 & M.11 & M.12 & M.13 & M.14 \\
\hline 101 & (Datta \& Mahapatra, 2010) & $\sqrt{ }$ & & $\sqrt{ }$ & $\sqrt{ }$ & & & $\sqrt{ }$ & $\sqrt{ }$ & & & & & & \\
\hline 102 & (Dellino et al., 2010b) & & $\sqrt{ }$ & & $\sqrt{ }$ & & $\sqrt{ }$ & $\sqrt{ }$ & $\sqrt{ }$ & $\sqrt{ }$ & & $\sqrt{ }$ & & & \\
\hline 103 & (Dellino et al., 2010a) & & $\sqrt{ }$ & & $\sqrt{ }$ & & $\sqrt{ }$ & $\sqrt{ }$ & $\sqrt{ }$ & $\sqrt{ }$ & & $\sqrt{ }$ & & & \\
\hline 104 & (Sun, Wei et al., 2010) & & $\sqrt{ }$ & $\sqrt{ }$ & & & $\sqrt{ }$ & $\sqrt{ }$ & & & & $\sqrt{ }$ & & & $\sqrt{ }$ \\
\hline 105 & (Yu et al., 2010) & & $\sqrt{ }$ & & & & $\sqrt{ }$ & $\sqrt{ }$ & $\sqrt{ }$ & & & $\sqrt{ }$ & $\sqrt{ }$ & & \\
\hline 106 & (Hazir et al., 2010) & & $\sqrt{ }$ & & & $\sqrt{ }$ & $\sqrt{ }$ & $\sqrt{ }$ & & $\sqrt{ }$ & & $\sqrt{ }$ & & & \\
\hline 107 & (Ardakani et al., 2009) & & $\sqrt{ }$ & $\sqrt{ }$ & & & $\sqrt{ }$ & $\sqrt{ }$ & $\sqrt{ }$ & & & & & & \\
\hline 108 & (Adida \& Joshi, 2009) & & $\sqrt{ }$ & & & & $\sqrt{ }$ & & & $\sqrt{ }$ & & $\sqrt{ }$ & & & \\
\hline 109 & (Dellino et al., 2009) & & $\sqrt{ }$ & & $\sqrt{ }$ & & $\sqrt{ }$ & $\sqrt{ }$ & $\sqrt{ }$ & $\sqrt{ }$ & & $\sqrt{ }$ & & & $\sqrt{ }$ \\
\hline 110 & (Dellino et al., 2009) & & & & $\sqrt{ }$ & & & & $\sqrt{ }$ & $\sqrt{ }$ & & $\sqrt{ }$ & & & \\
\hline 111 & (Wu \& Yeh, 2009) & & & & & & $\sqrt{ }$ & $\sqrt{ }$ & & & & & $\sqrt{ }$ & $\sqrt{ }$ & \\
\hline 112 & (Hasuike \& Ishii, 2009) & & $\sqrt{ }$ & $\sqrt{ }$ & & $\sqrt{ }$ & $\sqrt{ }$ & $\sqrt{ }$ & & & & $\sqrt{ }$ & & & \\
\hline 113 & (Hahn, 2008) & & & & & & $\sqrt{ }$ & & $\sqrt{ }$ & & & & & & $\sqrt{ }$ \\
\hline 114 & (Peng et al., 2008) & $\sqrt{ }$ & $\sqrt{ }$ & & & & $\sqrt{ }$ & $\sqrt{ }$ & & $\sqrt{ }$ & & $\sqrt{ }$ & $\sqrt{ }$ & & \\
\hline 115 & (Ardakani \& Noorossana, & & $\sqrt{ }$ & & $\sqrt{ }$ & & $\sqrt{ }$ & $\sqrt{ }$ & $\sqrt{ }$ & & & & & & \\
\hline 116 & (Stinstra \& den Hertog, 2008) & & $\sqrt{ }$ & & $\sqrt{ }$ & & $\sqrt{ }$ & $\sqrt{ }$ & $\sqrt{ }$ & & & & & & \\
\hline 117 & (Beyer \& Sendhoff, 2007) & $\sqrt{ }$ & $\sqrt{ }$ & $\sqrt{ }$ & & $\sqrt{ }$ & $\sqrt{ }$ & $\sqrt{ }$ & $\sqrt{ }$ & $\sqrt{ }$ & & $\sqrt{ }$ & & $\sqrt{ }$ & $\sqrt{ }$ \\
\hline 118 & (Wang \& Shan, 2007) & & & & $\sqrt{ }$ & & $\sqrt{ }$ & & $\sqrt{ }$ & & & & & & \\
\hline 119 & (Cohen et al., 2007) & & $\sqrt{ }$ & & & & $\sqrt{ }$ & & & $\sqrt{ }$ & $\sqrt{ }$ & $\sqrt{ }$ & & & $\sqrt{ }$ \\
\hline 120 & (Yamashita et al., 2007) & & $\sqrt{ }$ & & & & $\sqrt{ }$ & & & $\sqrt{ }$ & & $\sqrt{ }$ & & & \\
\hline 121 & (Janak et al., 2007) & & $\sqrt{ }$ & & & & $\sqrt{ }$ & & & $\sqrt{ }$ & $\sqrt{ }$ & $\sqrt{ }$ & & & $\sqrt{ }$ \\
\hline 122 & (Sharma et al., 2007) & $\sqrt{ }$ & & & & & & $\sqrt{ }$ & $\sqrt{ }$ & & & & & & \\
\hline 123 & (Singh et al., 2007) & $\sqrt{ }$ & & & & & $\sqrt{ }$ & $\sqrt{ }$ & & & & & & & \\
\hline 124 & (Popescu, 2007) & & $\sqrt{ }$ & & & & $\sqrt{ }$ & $\sqrt{ }$ & & $\sqrt{ }$ & & $\sqrt{ }$ & & & \\
\hline 125 & (Park \& Lee, 2006) & & $\sqrt{ }$ & & & & $\sqrt{ }$ & $\sqrt{ }$ & & & & $\sqrt{ }$ & & $\sqrt{ }$ & \\
\hline 126 & (Shahin, 2006) & $\sqrt{ }$ & & & & & & & & & & & & & \\
\hline 127 & (Khademi Zare et al., 2006) & & & & & $\sqrt{ }$ & $\sqrt{ }$ & $\sqrt{ }$ & & $\sqrt{ }$ & $\sqrt{ }$ & $\sqrt{ }$ & & & \\
\hline 128 & (Mula et al., 2006) & & $\sqrt{ }$ & $\sqrt{ }$ & & $\sqrt{ }$ & $\sqrt{ }$ & $\sqrt{ }$ & & $\sqrt{ }$ & & $\sqrt{ }$ & & & \\
\hline 129 & (Herroelen \& Leus, 2005) & & $\sqrt{ }$ & & & $\sqrt{ }$ & $\sqrt{ }$ & & & $\sqrt{ }$ & & $\sqrt{ }$ & & & $\sqrt{ }$ \\
\hline 130 & (Ko et al., 2005) & $\sqrt{ }$ & & & & & & $\sqrt{ }$ & $\sqrt{ }$ & & & & & & \\
\hline 131 & (Jin \& Branke, 2005) & & $\sqrt{ }$ & $\sqrt{ }$ & $\sqrt{ }$ & & $\sqrt{ }$ & $\sqrt{ }$ & & & & & & & \\
\hline 132 & (Chen, 2004) & & $\sqrt{ }$ & & & & & $\sqrt{ }$ & $\sqrt{ }$ & & & & & & \\
\hline 133 & (Herroelen \& Leus, 2004) & & $\sqrt{ }$ & & & & $\sqrt{ }$ & & & $\sqrt{ }$ & $\sqrt{ }$ & $\sqrt{ }$ & & & \\
\hline 134 & (Antoniol et al., 2004) & & & & & & $\sqrt{ }$ & & & $\sqrt{ }$ & & $\sqrt{ }$ & & & \\
\hline 135 & (Bertsimas \& Sim, 2004) & & $\sqrt{ }$ & & & & $\sqrt{ }$ & $\sqrt{ }$ & & $\sqrt{ }$ & & $\sqrt{ }$ & & $\sqrt{ }$ & \\
\hline 136 & (Romano et al., 2004) & $\sqrt{ }$ & & $\sqrt{ }$ & & & $\sqrt{ }$ & $\sqrt{ }$ & & $\sqrt{ }$ & & & & & \\
\hline 137 & (Lehman et al., 2004) & & $\sqrt{ }$ & & $\sqrt{ }$ & $\sqrt{ }$ & $\sqrt{ }$ & $\sqrt{ }$ & & & & & & & \\
\hline 138 & (Jin et al., 2003) & & $\sqrt{ }$ & & $\sqrt{ }$ & & $\sqrt{ }$ & $\sqrt{ }$ & $\sqrt{ }$ & & & $\sqrt{ }$ & & & \\
\hline 139 & (Messac \& Ismail-Yahaya, & & $\sqrt{ }$ & & & & & $\sqrt{ }$ & $\sqrt{ }$ & $\sqrt{ }$ & & & & & \\
\hline 140 & (Sandgren \& Cameron, 2002) & & $\sqrt{ }$ & & & & & $\sqrt{ }$ & & & & $\sqrt{ }$ & & & $\sqrt{ }$ \\
\hline 141 & (Simpson et al., 2001) & & & & $\sqrt{ }$ & & $\sqrt{ }$ & $\sqrt{ }$ & $\sqrt{ }$ & & & & & & \\
\hline 142 & (Jin et al., 2001) & & & & $\sqrt{ }$ & & & $\sqrt{ }$ & $\sqrt{ }$ & & & & & & \\
\hline 143 & (Chou \& Chang, 2001) & $\sqrt{ }$ & & & & & & $\sqrt{ }$ & & $\sqrt{ }$ & & & $\sqrt{ }$ & & \\
\hline 144 & (Lee \& Tang, 2000) & $\sqrt{ }$ & & & & & & $\sqrt{ }$ & & $\sqrt{ }$ & & & & & \\
\hline 145 & (Chen et al., 1999) & & $\sqrt{ }$ & & & & $\sqrt{ }$ & $\sqrt{ }$ & $\sqrt{ }$ & & & $\sqrt{ }$ & & & \\
\hline 146 & (Mavris et al., 1999) & & $\sqrt{ }$ & & $\sqrt{ }$ & & $\sqrt{ }$ & $\sqrt{ }$ & $\sqrt{ }$ & $\sqrt{ }$ & & $\sqrt{ }$ & & & $\sqrt{ }$ \\
\hline 147 & (Ahmed \& Sahinidis, 1998) & & $\sqrt{ }$ & $\sqrt{ }$ & & & $\sqrt{ }$ & $\sqrt{ }$ & & $\sqrt{ }$ & & $\sqrt{ }$ & & & $\sqrt{ }$ \\
\hline 148 & (Su \& Renaud, 1997) & & & & & & & $\sqrt{ }$ & $\sqrt{ }$ & & & $\sqrt{ }$ & & & \\
\hline 149 & (Myers et al., 1997) & & $\sqrt{ }$ & & $\sqrt{ }$ & & $\sqrt{ }$ & $\sqrt{ }$ & $\sqrt{ }$ & & & $\sqrt{ }$ & & & \\
\hline 150 & (Myers et al., 1990) & & $\sqrt{ }$ & & $\sqrt{ }$ & & $\sqrt{ }$ & $\sqrt{ }$ & $\sqrt{ }$ & & & & & & \\
\hline
\end{tabular}




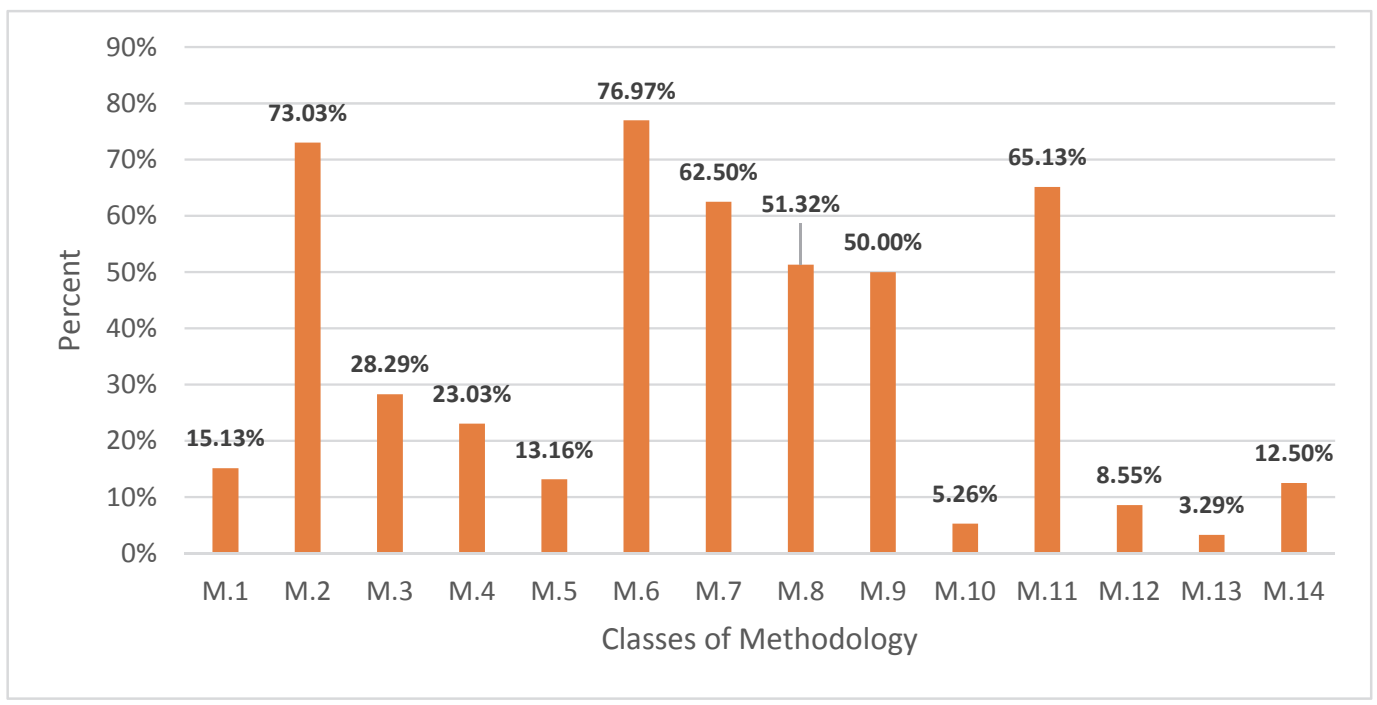

Fig. 10. The proportion of articles in each class of methodology

\section{Conclusion}

Accurate optimization of the process has been the main goal of many methods, since, most processes become to be more complex in practice. An unknown environment with variety types of uncertainties, intensive changes, uncontrollable factors, dynamic parameters over time, conflicting number of responses (multi-response), different types of data and so on, are some important circumstances which increase computational complexity in the problem. Therefore, some methods have been attracting intensive attention for tackling these conditions. Moreover, this study was aimed to systematically review some available literature on studies for such problems. The findings have revealed that there is still a gap between theory and practice in optimization, being evident in the fact that optimization methods could not still be used for many real-world problems. It is because most optimization methods have collided by some constraints and drawbacks such as inattention to uncertainties, the effect of noise factors, multiresponse condition, dynamic parameters and also intensive computation attempts. Furthermore, proposing comprehensive methods which can handle aforementioned circumstances, can be suggested for further research.

\section{References}

Aalaei, A., \& Davoudpour, H. (2017). A robust optimization model for cellular manufacturing system into supply chain management. International Journal of Production Economics, 183, 667-679.

Adida, E., \& Joshi, P. (2009). A robust optimisation approach to project scheduling and resource allocation. International Journal of Services Operations and Informatics, 4(2), 169-193.

Ahmed, S., \& Sahinidis, N. V. (1998). Robust Process Planning under Uncertainty. Industrial \& Engineering Chemistry Research, 37(5), 1883-1892.

Ait-Alla, A., Teucke, M., Lutjen, M., Beheshti-Kashi, S., \& Karimi, H. R. (2014). Robust production planning in fashion apparel industry under demand uncertainty via conditional value at risk. Mathematical Problems in Engineering, 2014.

Allahverdi, A. (2015). The third comprehensive survey on scheduling problems with setup times/costs. European Journal of Operational Research, 246(2), 345-378.

An, K., \& Ouyang, Y. (2016). Robust grain supply chain design considering post-harvest loss and harvest timing equilibrium. Transportation Research Part E: Logistics and Transportation Review, 88, 110 128.

An, Q., Bai, G., Yang, Y., Wang, C., Huang, Q., Liu, C., ... Xiang, B. (2016). Preparation optimization 
of ATO particles by robust parameter design. Materials Science in Semiconductor Processing, 42, 354-358.

Anderson, R., Wei, Z., Cox, I., Moore, M., \& Kussener, F. (2015). Monte Carlo Simulation Experiments for Engineering Optimisation. Studies in Engineering and Technology, 2(1), 97-102.

Antoniol, G., Di Penta, M., \& Harman, M. (2004). A robust search-based approach to project management in the presence of abandonment, rework, error and uncertainty. In Proceedings. 10th International Symposium on IEEE. (pp. 172-183).

Ardakani, M. K., \& Noorossana, R. (2008). A new optimization criterion for robust parameter design The case of target is best. International Journal of Advanced Manufacturing Technology, 38(9), 851859.

Ardakani, M. K., Noorossana, R., Akhavan Niaki, S. T., \& Lahijanian, H. (2009). Robust parameter design using the weighted metric method-the case of "the smaller the better." International Journal of Applied Mathematics and Computer Science, 19(1), 59-68.

Artigues, C., Leus, R., \& Talla Nobibon, F. (2013). Robust optimization for resource-constrained project scheduling with uncertain activity durations. Flexible Services and Manufacturing Journal, 25(1-2), 175-205.

Asafuddoula, M., Singh, H., \& Ray, T. (2015). Six-Sigma Robust Design Optimization using a Manyobjective Decomposition Based Evolutionary Algorithm. IEEE Transactions on Evolutionary Computation, 19(4), 490-507.

Asih, H. M., \& Chong, K. E. (2015). An Integrated Robust Optimization Model of Capacity Planning under Demand Uncertainty in Electronic Industry. International Journal of Mechanical \& Mechatronics Engineering IJMME-IJENS, 15(3), 88-96.

Ateme-Nguema, B. H., Etsinda-Mpiga, F., Dao, T., \& Songmene, V. (2012). An Approach-Based on Response Surfaces Method and Ant Colony System for Multi-Objective Optimization :A Case Study. In INTECH Open Access Publisher.

Auzins, J., Chate, A., Rikards, R., \& Skukis, E. (2015). Metamodeling and robust minimization approach for the identification of elastic properties of composites by vibration method. ZAMM .Journal of Applied Mathematics and Mechanics, 95(10), 1012-1026.

Bandi, C., \& Bertsimas, D. (2014). Robust option pricing. European Journal of Operational Research, 239(3), 842-853.

Ben-Tal, A., El Ghaoui, L., \& Nemirovski, A. (2009). Robust Optimization. Princeton University Press.

Bergman, B., Maré, J. De, Svensson, T., \& Loren, S. (2009). Robust design methodology for reliability: exploring the effects of variation and uncertainty. JohnWiley \& Sons, Ltd.

Bertsekas, D. (1998). Network Optimization: Continuous and Discrete Models. Belmont: Athena Scientific.

Bertsimas, D., Brown, D. B. D., \& Caramanis, C. (2011). Theory and Applications of Robust Optimization. SIAM Review, 53(3), 464-501.

Bertsimas, D., \& Sim, M. (2004). The Price of robustness. Operations Research, 52(1), 35-53.

Beyer, H. G., \& Sendhoff, B. (2007). Robust optimization - A comprehensive survey. Computer Methods in Applied Mechanics and Engineering, 196(33-34), 3190-3218.

Bossaghzadeh, I., Hejazi, S. R. and, \& Pirmoradi, Z. (2015). Developing Robust Project Scheduling Methods for Uncertain Parameters. Amirkabir International Journal of Science and Research (Modelling, Identification, Simulation \& Control), 47(1), 21-32.

Cai, L., Zhang, Z., Cheng, Q., Liu, Z., Gu, P., \& Qi, Y. (2016). An approach to optimize the machining accuracy retainability of multi-axis NC machine tool based on robust design. Precision Engineering, 43, 370-386.

Can, C., Wu, T., Hu, M., Weir, D. J., \& Chu, X. (2014). Accuracy vs. robustness: bi-criteria optimized ensemble of metamodels. In In Proceedings of the 2014 Winter Simulation Conference (pp. 616-627).

Cao, L., Jiang, P., Chen, Z., Zhou, Q., \& Zhou, H. (2015). Metamodel Assisted Robust Optimization under Interval Uncertainly Based on Reverse Model. IFAC-PapersOnLine, 48(28), 1178-1183.

Carson, Y., \& Maria, A. (1997). Simulation Optimization: Methods and Applications. In Proceedings of the 29th Conference on Winter Simulation, 118-126. 
Celano, G., Faraz, A., \& Saniga, E. (2014). Control charts monitoring product's loss to society. Quality and Reliability Engineering International, 30(8), 1393-1407.

Charnes, A., \& Cooper, W. W. (1977). Goal programming and multiple objective optimizations. European Journal of Operational Research, 1(1), 39-54.

Chen, C. (2004). Robust Design Based on Fuzzy Optimization. Tamsui Oxford Journal of Mathematical Sciences, 20(1), 65-72.

Chen, H.-W., Wong, W. K., \& Xu, H. (2012). An augmented approach to the desirability function. Journal of Applied Statistics, 39(3), 599-613.

Chen, W., Wiecek, M. M., \& Zhang, J. (1999). Quality utility : a Compromise Programming approach to robust design. Journal of Mechanical Design, 121(2), 179-187.

Cheng, Q., Xiao, C., Zhang, G., Gu, P., \& Cai, L. (2013). An analytical robust design optimization methodology based on axiomatic design principles. Quality and Reliability Engineering International, 30(7), 1059-1073.

Chevalier, C., Bect, J., Ginsbourger, D., Vazquez, E., Picheny, V., \& Richet, Y. (2014). Fast Parallel Kriging-Based Stepwise Uncertainty Reduction With Application to the Identification of an Excursion Set. Technometrics, 56(4), 455-465.

Chou, C. Y., \& Chang, C. . (2001). Minimum-Loss Assembly Tolerance Allocation by Considering Product Degradation and Time Value of Money. International Journal of Advanced Manufacturing Technology, 17(2), 139-146.

Cohen, I., Golany, B., \& Shtub, A. (2007). The Stochastic Time-Cost Tradeoff Problem: A Robust Optimization Approach. Networks, 45(2), 175-188.

Costa, N. R., Louren, J., \& Pereira, Z. L. (2011). Desirability function approach: A review and performance evaluation in adverse conditions. Chemometrics and Intelligent Laboratory Systems, 107(2), 234-244.

Dalton, S. K., Atamturktur, S., Farajpour, I., \& Juang, C. H. (2013). An optimization based approach for structural design considering safety, robustness, and cost. Engineering Structures, 57, 356-363.

Datta, S., \& Mahapatra, S. S. (2010). Modeling, simulation and parametric optimization of wire EDM process using response surface methodology coupled with grey-Taguchi technique. MultiCraft International Journal of Engineering, Science and Technology Extension, 2(5), 162-183.

Deb, K. (2011). Multi-objective optimization using evolutionary algorithms: an introduction, 3-34.

Deb, K., Pratap, A., Agarwal, S., \& Meyarivan, T. (2002). A fast and elitist multiobjective genetic algorithm: NSGA-II. IEEE Transactions on Evolutionary Computation, 6(2), 182-197.

Del Castillo, E., \& Montgomery, D. C. (1993). A nonlinear programming solution to the dual response problem. Journal of Quality Technology, 25, 199-204.

Dellino, G., Kleijnen, Jack, P. C., \& Meloni, C. (2015). Metamodel-Based Robust SimulationOptimization: An Overview. In Uncertainty Management in Simulation-Optimization of Complex Systems, 27-54.

Dellino, G., Kleijnen, J. P. C., \& Meloni, C. (2009). Robust simulation-optimization using metamodels. In Winter Simulation Conference (pp. 540-550).

Dellino, G., Kleijnen, J. P. C., \& Meloni, C. (2010a). Parametric and distribution-free bootstrapping in robust simulation-optimization. In Proceedings - Winter Simulation Conference (pp. 1283-1294).

Dellino, G., Kleijnen, J. P. C., \& Meloni, C. (2010). Robust optimization in simulation: Taguchi and Response Surface Methodology. International Journal of Production Economics, 125(1), 52-59.

Dellino, G., Kleijnen, J. P. C., \& Meloni, C. (2010b). Simulation-optimization under uncertainty through metamodeling and bootstrapping. Procedia - Social and Behavioral Sciences, 2(6), 7640-7641.

Dellino, G., Kleijnen, J. P. C., \& Meloni, C. (2012). Robust optimization in simulation: Taguchi and Krige combined. INFORMS Journal on Computing, 24(3), 471-484.

Dellino, G., Lino, P., Meloni, C., \& Rizzo, A. (2009). Kriging metamodel management in the design optimization of a CNG injection system. Mathematics and Computers in Simulation, 79(8), 23452360.

Demeulemeester, E., \& Herroelen, W. (2011). Robust Project Scheduling. Foundations and Trends ${ }^{\circledR}$ in Technology, Information and Operations Management, 3(3-4), 201-376. 
Ehrgott, M., Ide, J., \& Schöbel, A. (2014). Minmax robustness for multi-objective optimization problems. European Journal of Operational Research, 239(1), 17-31.

Erdbrügge, M., Kuhnt, S., \& Rudak, N. (2011). Joint optimization of independent multiple responses. Quality and Reliability Engineering International, 27(5), 689-704.

$\mathrm{Fu}, \mathrm{H}$., Sendhoff, B., Tang, K., \& Yao, X. (2012). Characterizing environmental changes in Robust Optimization Over Time. In WCCI 2012 IEEE Congress on Evolutionary Computation (pp. 10-15). IEEE.

Fu, H., Sendhoff, B., Tang, K., \& Yao, X. (2015). Robust optimization over time: Problem difficulties and benchmark problems. IEEE Transactions on Evolutionary Computation, 19(5), 731-745.

$\mathrm{Fu}$, N., Lau, H. C., \& Varakantham, P. (2015). Robust execution strategies for project scheduling with unreliable resources and stochastic durations. Journal of Scheduling, 18(6), 607-622.

Gabrel, V., Murat, C., \& Thiele, A. (2014). Recent advances in robust optimization: An overview. European Journal of Operational Research, 235(3), 471-483.

Gang, W., Wang, S., Augenbroe, G., \& Xiao, F. (2015). Robust optimal design of district cooling systems and the impacts of uncertainty and reliability. Energy and Buildings, 159, 265-275.

Gasior, D., \& Józefczyk, J. (2009). Application of uncertain variables to production planning in a class of manufacturing systems. Bulletin of the Polish Academy of Sciences: Technical Sciences, 57(3), 257-263.

Geletu, A., \& Li, P. (2014). Recent Developments in Computational Approaches to Optimization under Uncertainty and Application in Process Systems Engineering. ChemBioEng Reviews, 1(4), 170-190.

Ghodratnama, A., Tavakkoli-Moghaddam, R., \& Azaron, A. (2015). Robust and fuzzy goal programming optimization approaches for a novel multi-objective hub location-allocation problem: A supply chain overview. Applied Soft Computing Journal, 37, 255-276.

Goberna, M. A., Jeyakumar, V., Li, G., \& Vicente-Perez, J. (2015). Robust solutions to multi-objective linear programs with uncertain data. European Journal of Operational Research, 242(3), 730-743.

Goerigk, M., \& Schöbel, A. (2015). Algorithm Engineering in Robust Optimization. In Algorithm engineering (pp. 245-279). Springer International Publishing.

Gorissen, B. L. (2015). Robust Fractional Programming. Journal of Optimization Theory and Applications, 166(2), 508-528.

Grossmann, I. E., Apap, R. M., Calfa, B. A., Garcia-Herreros, P., \& Zhang, Q. (2016). Recent Advances in Mathematical Programming Techniques for the Optimization of Process Systems under Uncertainty. Computer and Chemical Engineering, 91, 3-14.

Gul, G., \& Zoubir, A. M. (2017). Minimax Robust Hypothesis Testing. IEEE Transactions on Information Theory.

Gulpinar, N., \& Pachamanova, D. (2013). A robust optimization approach to asset-liability management under time-varying investment opportunities. Journal of Banking and Finance, 37(6), 2031-2041.

Gyulai, D., Kadar, B., \& Monosotori, L. (2015). Robust production planning and capacity control for flexible assembly lines. IFAC Proceedings Volumes (IFAC-PapersOnline), 48(3), 2312-2317.

H.Myers, R., C.Montgomery, D., \& Anderson-Cook, M, C. (2016). Response Surface Methodology: Process and Product Optimization Using Designed Experiments-Fourth Edition. Wiley Series in Probability and Statistics.

Hahn, E. D. (2008). Mixture densities for project management activity times: A robust approach to PERT. European Journal of Operational Research, 188(2), 450-459.

Hao, X., Lin, L., \& Gen, M. (2014). An effective multi-objective EDA for robust resource constrained project scheduling with uncertain durations. Procedia Computer Science, 36, 571-578.

Hasani, A., \& Khosrojerdi, A. (2016). Robust global supply chain network design under disruption and uncertainty considering resilience strategies: A parallel memetic algorithm for a real-life case study. Transportation Research Part E: Logistics and Transportation Review, 87, $20-52$.

Hasuike, T., \& Ishii, H. (2009). Robust Expectation Optimization Model Using the Possibility Measure for the Fuzzy Random. Applications of Soft Computing, 58, 285-294.

Hazir, O., Haouari, M., \& Erel, E. (2010). Robust scheduling and robustness measures for the discrete time/cost trade-off problem. European Journal of Operational Research, 207(2), 633-643. 
He, Z., Wang, J., Jinho, O., \& H. Park, S. (2010). Robust optimization for multiple responses using response surface methodology. Applied Stochastic Models in Business and Industry, 26, 157-171.

Herroelen, W., \& Leus, R. (2004). Robust and reactive project scheduling: a review and classification of procedures. International Journal of Production Research, 42(8), 1599-1620.

Herroelen, W., \& Leus, R. (2005). Project scheduling under uncertainty: Survey and research potentials. European Journal of Operational Research, 165(2), 289-306.

HO, C.-J. (1989). Evaluating the impact of operating environments on MRP system nervousness. The International Journal of Production Research, 27(7), 1115-1135.

Huang, Y., Zhang, Y., Li, N., \& Chambers, J. (2016). A Robust Gaussian Approximate Fixed-Interval Smoother for Nonlinear Systems With Heavy-Tailed Process and Measurement Noises, 23(4), 468472.

Hwang, C. ., \& Masud, A. S. M. (2012). Multiple objective decision making-methods and applications: a state-of-the-art survey (Vol. 164). Springer Science \& Business Media.

Iancu, D. a, \& Trichakis, N. (2014). Pareto Efficiency in Robust Optimization. Management Science, 60(1), 130-147.

Ide, J., \& Schobel, A. (2016). Robustness for uncertain multi-objective optimization: a survey and analysis of different concepts. OR Spectrum, 38(1), 235-271.

Janak, S. L., Lin, X., \& Floudas, C. A. (2007). A new robust optimization approach for scheduling under uncertainty. II. Uncertainty with known probability distribution. Computers and Chemical Engineering, 31(3), 171-195.

Jin, L., Huang, G. H., Cong, D., \& Fan, Y. R. (2014). A Robust Inexact Joint-optimal alfa cut Interval Type-2 Fuzzy Boundary Linear Programming (RIJ-IT2FBLP) for energy systems planning under uncertainty. International Journal of Electrical Power and Energy Systems, 56, 19-32.

Jin, R., Chen, W., \& Simpson, T. W. (2001). Comparative studies of metamodelling techniques under multiple modelling criteria. Structural and Multidisciplinary Optimization, 23(1), 1-13.

Jin, R., Du, X., \& Chen, W. (2003). The use of metamodeling techniques for optimization under uncertainty. Structural and Multidisciplinary Optimization, 25(2), 99-116.

Jin, Y., \& Branke, J. (2005). Evolutionary optimization in uncertain environments-a survey. IEEE Transactions on Evolutionary Computation, 9(3), 303-317.

Jin, Y., Tang, K., Yu, X., Sendhoff, B., \& Yao, X. (2013). A framework for finding robust optimal solutions over time. Memetic Computing, 5(1), 3-18.

Jurecka, F. (2007). Robust Design Optimization Based on Metamodeling Techniques. PhD Thesis.

Kartal-Koç, E., Batmaz, İ., \& Weber, G.-W. (2012). Robust Regression Metamodeling of Complex Systems: The Case of Solid Rocket Motor Performance Metamodeling. In Advances in Intelligent Modelling and Simulation (pp. 221-251). Springer Berlin Heidelberg.

Khademi Zare, H., Fatemi Ghomi, S. M. T., \& Karimi, B. (2006). Developing a heuristic algorithm for order production planning using network models under uncertainty conditions. Applied Mathematics and Computation, 182(2), 1208-1218.

Khaledi, K., Miro, S., König, M., \& Schanz, T. (2014). Robust and reliable metamodels for mechanized tunnel simulations. Computers and Geotechnics, 61, 1-12.

Khan, J., Teli, S. ., \& Hada, B. . (2015). Reduction Of Cost Of Quality By Using Robust Design : A Research Methodology. International Journal of Mechanical and Industrial Technology, 2(2), 122128.

Klimek, M., \& Lebkowski, P. (2011). Resource allocation for robust project scheduling. Bulletin of the Polish Academy of Sciences-Technical Sciences, 59(1), 51-55.

Ko, Y., Kim, K., \& Jun, C. (2005). A New Loss Function-Based Method for Multiresponse Optimization. Journal of Quality Technology, 37(1), 50-59.

Kokkinos, O., \& Papadopoulos, V. (2016). Robust design with Variability Response Functions; an alternative approach. Structural Safety, 59, 1-8.

Kolluri, S. S., Esfahani, I. J., \& Yoo, C. (2016). Robust fuzzy and multi-objective optimization approaches to generate alternate solutions for resource conservation of eco-industrial park involving various future events. Process Safety and Environmental Protection, 103, 424-441. 
Krige, D. G. (1951). A statistical approach to some mine valuation and allied problems on the Witwatersrand.

Kuhn, K., Raith, A., Schmidt, M., \& Schobel, A. (2016). Bi-objective robust optimisation. European Journal of Operational Research, 252(2), 418-431.

Lambrechts, O., Demeulemeester, E., \& Herroelen, W. (2011). Time slack-based techniques for robust project scheduling subject to resource uncertainty. Annals of Operations Research, 186(1), 443-464.

Lee, C. L., \& Tang, G. R. (2000). Tolerance design for products with correlated characteristics. Mechanism and Machine Theory, 35(12), 1675-1687.

Lehman, J. S., Santner, T. J., \& Notz, W. I. (2004). Designing Computer Experiments To Determine Robust Control Variables. Statistica Sinica, 14(1), 571-590.

Lersteau, C., Rossi, A., \& Sevaux, M. (2016). Robust scheduling of wireless sensor networks for target tracking under uncertainty. European Journal of Operational Research, 252(2), 407-417.

Lin, D. K. J., \& Tu, W. (1995). Dual response surface optimization. Journal of Quality Technology, 27(1), 34-39.

Ling, A., Sun, J., Xiu, N., \& Yang, X. (2017). Robust Two-stage Stochastic Linear Optimization with Risk Aversion. European Journal of Operational Research, 256(1), 215-229.

Liu, X., Yue, R.-X., \& Chatterjee, K. (2015). Model-robust R-optimal designs in linear regression models. Journal of Statistical Planning and Inference, 167, 135-143.

Lopez Martin, M. M., Garcia Garcia, C. B., Garcia Perez, J., \& Sanchez Granero, M. A. (2012). An alternative for robust estimation in project management. European Journal of Operational Research, 220(2), 443-451.

Margellos, K., Goulart, P., \& Lygeros, J. (2014). On the road between robust optimization and the scenario approach for chance constrained optimization problems. IEEE Transactions on Automatic Control, 59(8), 2258-2263.

Marler, R. T., \& Arora, J. S. (2004). Survey of multi-objective optimization methods for engineering. Structural and Multidisciplinary Optimization, 26(6), 369-395.

Marti, K. (2015). Stochastic Optimization Methods- Third Edition. Berlin: Springer.

Martınez-Frutos, E. J., \& Marti-Montrull, P. (2012). Metamodel-based multi-objective robust design optimization of structures. Computer Aided Optimum Design in Engineering XII, 125, 35-45.

Mavris, D. N., Bandte, O., \& DeLaurentis, D. A. (1999). Robust Design Simulation: A Probabilistic Approach to Multidisciplinary Design. Journal of Aircraft, 36(1), 298-307.

Mavrotas, G., Figueira, J. R., \& Siskos, E. (2015). Robustness analysis methodology for multi-objective combinatorial optimization problems and application to project selection. Omega, 52, 142-155.

Messac, A., \& Ismail-Yahaya, A. (2002). Multiobjective robust design using physical programming. Structural and Multidisciplinary Optimization, 23(5), 357-371.

Miettinen, K. (2012). Nonlinear multiobjective optimization (Vol. 12). Springer Science \& Business Media.

Miranda, A. N. A. K., \& Castillo, E. D. E. L. (2011). Robust Parameter Design Optimization of Simulation Experiments Using Stochastic Perturbation Methods. Journal of the Operational Research Society, 62(1), 198-205.

Mirmajlesi, S. R., \& Shafaei, R. (2016). An integrated approach to solve a robust forward/reverse supply chain for short lifetime products. Computers \& Industrial Engineering, 97, 222-239.

Mirzapour Al-e-Hashem, S. M. J., Malekly, H., \& Aryanezhad, M. B. (2011). A multi-objective robust optimization model for multi-product multi-site aggregate production planning in a supply chain under uncertainty. International Journal of Production Economics, 134(1), 28-42.

Modarres, M., \& Izadpanahi, E. (2016). Aggregate production planning by focusing on energy saving: A robust optimization approach. Journal of Cleaner Production, 133, 1074-1085.

Mula, J., Poler, R., García-Sabater, G. S., \& Lario, F. C. (2006). Models for production planning under uncertainty: A review. International Journal of Production Economics, 103(1), 271-285.

Myers, R. H., Khuri, A. I., \& Vining, G. (1990). Response Surface Alternatives to the Taguchi Robust Parameter Design Approach. The American Statistician, 46(2), 131-139.

Myers, R. H., KIM, Y., \& Griffiths, K. L. (1997). Response Surface Methods and the Use of Noise 
Variables. Journal of Quality Technology, 29(4), 429-440.

Namazian, A., \& Yakhchali, S. H. (2016). Modeling and Solving Project Portfolio and Contractor Selection Problem Based on Project Scheduling under Uncertainty. Procedia - Social and Behavioral Sciences, 226, 35-42.

Ng, L. Y., Chemmangattuvalappil, N. G., \& Ng, D. K. S. (2015). Robust chemical product design via fuzzy optimisation approach. Computers and Chemical Engineering, 83, 186-202.

Nha, V. T., Shin, S., \& Jeong, S. H. (2013). Lexicographical dynamic goal programming approach to a robust design optimization within the pharmaceutical environment. European Journal of Operational Research, 229(2), 505-517.

Oros, A., Topa, M., Amariutei, R. D., Buzo, A., \& Rafaila, M. (2014). Robust Response Design for Heterogeneous Systems based on Metamodels. In Electronics, Circuits and Systems (ICECS), 2014 21st IEEE International Conference (pp. 602-605). IEEE.

Palacios, J. J., Puente, J., Vela, C. R., \& Gonzalez-Rodrriguez, I. (2016). Robust multiobjective optimisation for fuzzy job shop problems. Applied Soft Computing.

Park, C., \& Leeds, M. (2016). A Highly Efficient Robust Design Under Data Contamination. Computers \& Industrial Engineering, 93, 131-142.

Park, G., \& Lee, T. (2006). Robust Design : An Overview. Aiaa Journal, 44(1), 181-191.

Park, S. (1996). Robust design and Analysis for Quality Engineering. Boom Koninklijke Uitgevers.

Park, S., \& Antony, J. (2008). Robust design for quality engineering and six sigma. World Scientific Publishing Co Inc.

Parsopoulos, K. E., \& Vrahatis, M. N. (2002). Particle swarm optimization method in multiobjective problems. Proceedings of the 2002 ACM Symposium on Applied Computing, 603-607.

Peng, H. P., Jiang, X. Q., Xu, Z. G., \& Liu, X. J. (2008). Optimal tolerance design for products with correlated characteristics by considering the present worth of quality loss. International Journal of Advanced Manufacturing Technology, 39(1), 1-8.

Peri, D. (2016). Robust Design Optimization for the refit of a cargo ship using real seagoing data. Ocean Engineering, 123, 103-115.

Persson, J., \& Ölvander, J. (2013). Comparison of different uses of metamodels for robust design optimization. In American Institute of Aeronautics and ... (p. 1039).

Phadke, M. S. (1989). Quality Engineering Using Robust Design. Prentice Hall PTR.

Pishvaee, M. S., \& Fazli Khalaf, M. (2016). Novel robust fuzzy mathematical programming methods. Applied Mathematical Modelling, 40, 407-418.

Pishvaee, M. S., Rabbani, M., \& Torabi, S. A. (2011). A robust optimization approach to closed-loop supply chain network design under uncertainty. Applied Mathematical Modelling, 35(2), 637-649.

Pishvaee, M. S., \& Razmi, J. (2012). Environmental supply chain network design using multi-objective fuzzy mathematical programming. Applied Mathematical Modelling, 36(8), 3433-3446.

Pishvaee, M. S., Razmi, J., \& Torabi, S. A. (2012). Robust possibilistic programming for socially responsible supply chain network design: A new approach. Fuzzy Sets and Systems, 206, 1-20.

Pishvaee, M. S., \& Torabi, S. A. (2010). A possibilistic programming approach for closed-loop supply chain network design under uncertainty. Fuzzy Sets and Systems, 161(20), 2668-2683.

Popescu, I. (2007). Robust Mean-Covariance Solutions for Stochastic Optimization. Operations Research, 55(1), 98-112.

Rathod, V., Yadav, O. P., Rathore, A., \& Jain, R. (2013). Optimizing reliability-based robust design model using multi-objective genetic algorithm. Computers \& Industrial Engineering, 66(2), 301-310.

Romano, D., Varetto, M., \& Vicario, G. (2004). Multiresponse Robust Design: A general Framework Based on Combined Array. Journal of Quality Technology, 36(1), 27.

Sahali, M. A., Serra, R., Belaidi, I., \& Chibane, H. (2015). Bi-objective robust optimization of machined surface quality and productivity under vibrations limitation. In MATEC Web of Conferences (Vol. 20). EDP Sciences.

Salmasnia, A., Ameri, E., \& Niaki, S. T. A. (2016). A robust loss function approach for a multi-objective redundancy allocation problem. Applied Mathematical Modelling, 40(1), 635-645.

Salmasnia, A., Bashiri, M., \& Salehi, M. (2013). A robust interactive approach to optimize correlated 
multiple responses. International Journal of Advanced Manufacturing Technology, 67(5-8), 19231935.

Salmasnia, A., Mokhtari, H., \& Kamal Abadi, I. N. (2012). A robust scheduling of projects with time, cost, and quality considerations. International Journal of Advanced Manufacturing Technology, 60(58), 631-642.

Salomon, S., Avigad, G., Fleming, P. J., \& Purshouse, R. C. (2014). Active robust optimization: Enhancing robustness to uncertain environments. IEEE Transactions on Cybernetics, 44(11), 22212231.

Sandgren, E., \& Cameron, T. M. (2002). Robust design optimization of structures through consideration of variation. Computers and Structures, 80(20), 1605-1613.

Shahin, A. (2006). Robust design: an advanced quality engineering methodology for change management in the third millennium. In Proceedings of the 7th International Conference of Quality Managers (pp. 201-212).

Sharma, N. K., \& Cudney, E. A. (2011). Signal-to-Noise ratio and design complexity based on Unified Loss Function - LTB case with Finite Target. International Journal of Engineering, Science and Technology, 3(7), 15-24.

Sharma, N. K., Cudney, E. A., Ragsdell, K. M., \& Paryani, K. (2007). Quality Loss Function - A Common Methodology for Three Cases. Journal of Industrial and Systems Engineering, 1(3), 218234.

Simpson, T. W., Poplinski, J. D., Koch, P. N., \& Allen, J. K. (2001). Metamodels for Computer-based Engineering Design: Survey and recommendations. Engineering With Computers, 17(2), 129-150.

Singh, J., Frey, D. D., Soderborg, N., \& Jugulum, R. (2007). Compound Noise: Evaluation as a Robust Design Method. Quality and Reliability Engineering International, 23(3), 517-543.

Steimel, J., \& Engell, S. (2015). Conceptual design and optimization of chemical processes under uncertainty by two-stage programming. Computers and Chemical Engineering, 81, 200-217.

Stinstra, E., \& den Hertog, D. (2008). Robust optimization using computer experiments. European Journal of Operational Research, 191(3), 816-837.

$\mathrm{Su}$, J., \& Renaud, E. . (1997). Automatic differentiation in robust optimization. AIAA Journal, 35(6), 1072-1079.

Suman, B., \& Kumar, P. (2006). A Survey of Simulated Annealing as a Tool for Single and Multiobjective Optimization on JSTOR. Journal of the Operational Research Society, 57(10), 11431160.

Sun, G., Fang, J., Tian, X., Li, G., \& Li, Q. (2015). Discrete robust optimization algorithm based on Taguchi method for structural crashworthiness design. Expert Systems with Applications, 42(9), 44824492.

Sun, W., Dong, R., \& Xu, H. (2010). A novel non-probabilistic approach using interval analysis for robust design optimization. Journal of Mechanical Science and Technology, 23(12), 3199-3208.

Tabrizi, B. H., \& Ghaderi, S. F. (2016). A robust bi-objective model for concurrent planning of project scheduling and material procurement. Computers \& Industrial Engineering, 98, 11-29.

Takriti, S., \& Ahmed, S. (2004). On robust optimization of two-stage systems. Mathematical Programming, 99(1), 109-126.

Talaei, M., Farhang Moghaddam, B., Pishvaee, M. S., Bozorgi-Amiri, A., \& Gholamnejad, S. (2016). A robust fuzzy optimization model for carbon-efficient closed-loop supply chain network design problem: A numerical illustration in electronics industry. Journal of Cleaner Production, 113, 662673.

Tsai, T.-N., \& Liukkonen, M. (2016). Robust parameter design for the micro-BGA stencil printing process using a fuzzy logic-based Taguchi method. Applied Soft Computing, 48, 124-136.

Ur Rehman, S., Langelaar, M., \& van Keulen, F. (2014). Efficient Kriging-based robust optimization of unconstrained problems. Journal of Computational Science, 5(6), 872-881.

Wang, G., \& Shan, S. (2007). Review of Metamodeling Techniques in Support of Engineering Design Optimization. Journal of Mechanical Design, 129(4), 370-380.

Wang, G., \& Shan, S. (2011). Review of Metamodeling Techniques for Product Design with 
Computation-intensive Processes. Proceedings of the Canadian Engineering ..., 1-11.

Wang, H., Lu, Z., Zhao, H., \& Feng, H. (2015). Application of Parallel Computing in Robust Optimization Design Using MATLAB. In Instrumentation and Measurement, Computer, Communication and Control (IMCCC), 2015 Fifth International Conference (pp. 1228-1231). IEEE.

Wang, J., Ma, Y., Ouyang, L., \& Tu, Y. (2016). A new Bayesian approach to multi-response surface optimization integrating loss function with posterior probability. European Journal of Operational Research, 249(1), 231-237.

Wang, S., \& Pedrycz, W. (2015). Robust Granular Optimization: A Structured Approach for Optimization under Integrated Uncertainty. IEEE Transactions on Fuzzy Systems, 23(5), 1372-1386.

Wu, D., Gao, W., Wang, C., Tangaramvong, S., \& Tin-Loi, F. (2016). Robust fuzzy structural safety assessment using mathematical programming approach. Fuzzy Sets and Systems, 293, 30-49.

$\mathrm{Wu}, \mathrm{F}$. (2015). Robust Design of Mixing Static and Dynamic Multiple Quality Characteristics. World Journal of Engineering and Technology, 3(3), 72-77.

Wu, F.-C., \& Yeh, C.-H. (2009). Robust design of nonlinear multiple dynamic quality characteristics. Computers and Industrial Engineering, 56(4), 1328-1332.

Wu, J., Gao, J., Luo, Z., \& Brown, T. (2016). Robust topology optimization for structures under interval uncertainty. Advances in Engineering Software, 99, 36-48.

Wu, J., Luo, Z., Zhang, Y., \& Zhang, N. (2014). An interval uncertain optimization method for vehicle suspensions using Chebyshev metamodels. Applied Mathematical Modelling, 38(15), 3706-3723.

$\mathrm{Wu}, \mathrm{Y}$., Sun, Y., \& Chen, L. (2016). Robust adaptive finite-time synchronization of nonlinear resource management system. Neurocomputing, 171, 1131-1138.

Yamashita, D. S., Armentano, V. A., \& Laguna, M. (2007). Robust optimization models for project scheduling with resource availability cost. Journal of Scheduling, 10(1), 67-76.

Yanikoglu, I., Hertog, D. Den, \& Kleijnen, J. P. C. (2016). Robust Dual Response Optimization. IIE Transactions, 48(3), 298-312.

$\mathrm{Yu}$, A., \& Zeng, B. (2015). Exploring the Modeling Capacity of Two-Stage Robust Optimization : Variants of Robust. IEEE Transactions on Power Systems, 30(1), 109-122.

Yu, X., Yaochu, J., Ke, T., \& Xin, Y. Y. (2010). Robust optimization over time -A new perspective on dynamic optimization problems. In Evolutionary Computation (CEC), 2010 IEEE Congress (pp. 16). IEEE.

Zadeh, L. (1963). Optimality and non-scalar-valued performance criteria. Automatic Control, IEEE Transactions on, 8(1), 59-60.

Zhang, D., \& Lu, Q. (2016). Robust Regression Analysis with LR-Type Fuzzy Input Variables and Fuzzy Output Variable. Journal of Data Analysis and Information Processing, 4(2), 64-80.

Zhang, J., \& Qiao, C. (2015). A bi-objective Model for Robust Resource- constrained Project Scheduling Problem with Random Activity Durations. In Networking, Sensing and Control (ICNSC), 2015 IEEE 12th International Conference (pp. 28-32). IEEE.

Zhang, M., \& Guan, Y. (2014). Two-stage robust unit commitment problem. European Journal of Operational Research, 234(3), 751-762.

Zhang, Q., Morari, M. F., Grossmann, I. E., Sundaramoorthy, A., \& Pinto, J. M. (2016). An adjustable robust optimization approach to scheduling of continuous industrial processes providing interruptible load. Computers and Chemical Engineering, 86, 106-119.

Zhang, S., Zhu, P., Chen, W., \& Arendt, P. (2013). Concurrent treatment of parametric uncertainty and metamodeling uncertainty in robust design. Structural and Multidisciplinary Optimization, 47(1), 6376.

Zhang, W., Zhang, Y., Bai, X., Liu, J., Zeng, D., \& Qiu, T. (2016). A robust fuzzy tree method with outlier detection for combustion models and optimization. Chemometrics and Intelligent Laboratory Systems, 158, 130-137.

Zhu, L., Ma, Y., \& Zhang, L. (2013). The robust design of EOQ considering the compound effect of both noise uncertainty and meta-modeling uncertainty. In Computational Intelligence and Design (ISCID), 2013 Sixth International Symposium (Vol. 1, pp. 173-177). IEEE. 
(C) 2017 by the authors; licensee Growing Science, Canada. This is an open access article distributed under the terms and conditions of the Creative Commons Attribution (CCBY) license (http://creativecommons.org/licenses/by/4.0/). 